\title{
O GOVERNO E A ADMINISTRAÇÃO LOCAL NA ESPANHA: SOBRE AS ALTERAÇÕES DOS LIMITES MUNICIPAIS
}

\author{
LOCAL GOVERNMENT AND ADMINISTRATION IN SPAIN: ON CHANGES ON \\ MUNICIPAL BOUNDARIES
}

\section{EL GOBIERNO Y LA ADMINISTRACIÓN LOCAL EN ESPAÑA: SOBRE LAS ALTERACIONES DE LOS TÉRMINOS MUNICIPALES}

\author{
Jaime Rodríguez-Arana Muñoz*
}

Sumário: Introducción. 1. Una Aproximación Multidiciplinar a la Realidad Local. 2. P anorámica General y Particular. 3. Alteraciones Territoriales: Fusiones e Incorporaciones. 4. Experiencias de Fusiones Municipales. 5. La Cuestión Competencial: el Tema Pendiente. Reflexión Final. Bibliografia.

Resumo: A questão dos espaços territoriais locais e seus governos e administrações é um assunto de discussão permanente e, hoje em dia, de grande atualidade. O debate acadêmico e político, por exemplo, acerca do tamanho dos municípios é permanente (...). Certamente, do Estado tem transferido às comunidades autônomas numerosas competências. Contudo, está pendente de realização a transferência harmônica de competências das comunidades autônomas aos entes locais a partir da lógica da subsidiariedade, a partir da lógica de que as pessoas recebam os

\footnotetext{
* Catedrático de Direito Administrativo da Universidade da Coruña e Presidente do Foro Iberoamericano de Derecho Administrativo.
} 
melhores serviços para que possam melhorar, vale a redundância, suas condições de vida e assim poderem ser mais livres pessoal e solidariamente.

Palavras-chave: governo; administração local; Espanha; municípios; autonomia; subsidiariedade.

Abstract: The issue of local territorial spaces and their governments and administrations is a subject of ongoing discussion and, today, of great current relevance. The academic and political debate, for example, about the size of municipalities is permanent (...). Certainly, the state has transferred to the autonomous communities numerous powers. However, it is pending a consistent transfer of powers from autonomous communities to local bodies based on the logic of subsidiarity, on the logic that people receive the best services in order that they can improve, it is worth the redundancy, their living conditions and therefore be freer personal and solidarily.

Keywords: Government; Local Administration; Spain; Municipalities; Autonomy; Subsidiarity.

Resumen: La cuestión de los espacios territoriales locales y sus Gobiernos y Administraciones es un asunto de discusión permanente y, hoy en día, de gran actualidad. El debate académico y político, por ejemplo, acerca del tamaño de los municipios es permanente(...) Ciertamente, desde el Estado se han transferido a las Comunidades Autónomas numerosas competencias. Sin embargo, todavía esta pendiente de realización, el congruente traspaso de competencias de las Comunidades Autónomas a los Entes locales desde la lógica de la subsidiariedad, desde la lógica de que las personas reciban los mejores servicios que puedan mejorar, valga la redundancia, sus condiciones de vida y así poder ser más libres personal y solidariamente. 


\section{Cadernos do Programa de Pós-Graduação em Direito/UFRGS}

http://seer.ufrgs.br/ppgdir - ISSN: 1678-5029 - E-ISSN: 2317-8558

\section{Volume VIII | Número 2 | Ano 2013}

Palabras clave: gobierno; administración local; España; municípios; autonomia; subsidiariedade.

\section{INTRODUCCIÓN}

La cuestión de los espacios territoriales locales y sus Gobiernos y Administraciones es, desde luego, un asunto de discusión permanente y, hoy en día, de gran actualidad. El debate académico y político, por ejemplo, acerca del tamaño de los municipios es permanente. En la propia Historia de España, sin ir más lejos, este polémico tema lo encontramos, desde la Constitución de Cádiz en 1812 hasta nuestros días sea cuál sea la forma de gobierno, sea cuál sea el partido político en el poder.

Es lógico que así sea por que siendo como es la Administración y el Gobierno local la estructura política y administrativa primaria, la primera con la que se topa la persona, ésta ha de tener una organización y unos medios adecuados para cumplir sus tareas de mejora de las condiciones de vida de los vecinos. Sin embargo, al menos en España, tras la Constitución de 1978, los Entes locales han sido las Administraciones y Gobiernos territoriales más olvidados por el sistema político, probablemente, como se ha dicho y escrito hasta la saciedad, porque había que cuidar y alimentar adecuadamente a las Comunidades Autónomas, de emergencia y creación constitucional. Hasta tal punto esto es así que en la agenda política surgió no hace mucho una expresión para llamar la atención acerca de la relevancia de estas instituciones públicas y su sistemática preterición en la acción pública de los últimos tiempos: el pacto local, también denominado, según los casos y las circunstancias, la segunda descentralización.

Ciertamente, desde el Estado se han transferido a las Comunidades Autónomas numerosas competencias. Sin embargo, todavía esta pendiente de realización, el congruente traspaso de competencias de las Comunidades Autónomas a los Entes locales desde la lógica de la subsidiariedad, desde la lógica de que las personas reciban los mejores servicios que puedan mejorar, valga la redundancia, sus condiciones de vida y así poder ser más libres personal y solidariamente. Esta segunda descentralización esta pendiente, aunque es verdad que en algunas 
Comunidades Autónomas se han adoptado algunas medidas en esta dirección, sin que el proceso, ni mucho menos, haya alcanzado un volumen de transferencias razonable.

El análisis de la realidad político-administrativa local entre nosotros, debe hacerse desde la perspectiva del derecho, por supuesto, pero también, como desarrollaré en el siguiente parágrafo, desde la óptica de la ciencia política. Por una razón poderosa, los Entes locales son estructuras de servicio objetivo al interés general, por supuesto, pero por su carácter representativo de la ciudadanía y la forma de elección de sus regidores, tienen un obvio carácter político que no se puede perder de vista. Es decir, no son exclusivamente Entes públicos dotados de autonomía administrativa o de mera gestión, tienen autonomía política, por mucho que algunas doctrinas intenten supeditar la naturaleza de la autonomía al hecho de disponer de una Asamblea legislativa, a la capacidad de autoformación del máximo rango.

Los postulados del pensamiento abierto, plural, dinámico y complementario, tan importantes en las ciencias sociales, han de facilitar un acercamiento de tal naturaleza a la realidad local, una realidad que constituye el primer espacio de encuentro para la persona con el interés público. Un concepto, éste de interés público, que tiene una dimensión compuesta y que pude ser gestionado y gobernado desde cada Ente público de acuerdo con su imbricación en la esfera de competencias y atribuciones propias. Por eso, para estar en mejores condiciones de comprender el alcance y operatividad de los Entes locales, sería menester disponer de un estudio en el que se clarificara el ámbito de competencias de cada Ente territorial, tanto desde la perspectiva constitucional y autonómica, como desde una consideración del interés público local y las competencias que en un estado compuesto como el español debieran corresponder a los Entes locales, sean Ayuntamientos, Diputaciones, Consejos o cabildos insulares.

Con alguna frecuencia los estudios jurídico-administrativos y políticos sobre las estructuras políticas y administrativas se olvidan de un elemento central: del ciudadano, en este caso del vecino. Tal preterición constituye todavía una herencia del modelo de Estado burocrático que todavía habita en las mentes de no pocos gestores y académicos, más preocupados de análisis y estudios endogámicos que se agotan y se cierran sobre sí mismos. En cambio, cuando el centro de la cuestión pasa del la estructura a la persona, de la institución al ciudadano, entonces las reflexiones y las propuestas, de uno u otro signos alcanza parámetros de 
racionalidad que permiten comprender mejor el objeto de estudio y dar a cada actor el valor que realmente tiene.

El marco constitucional y estatutario va a estar necesariamente presente en nuestro análisis. Porque es una premisa metodológica y sustancial de cualquier investigación sobre los Entes locales en España y porque para un jurista son sus principales armas para la tarea. En este sentido, también vamos a trabajar en el contexto de la ya "vieja" ley de bases de 1985 así como, para el caso gallego, en el ámbito de la legislación propia en la materia.

Las experiencias comparadas acerca de cómo han resuelto y resuelven la cuestión local proporcionan, desde luego, aportaciones muy importantes en orden a pensar posibles soluciones para nosotros. También existen legislaciones autonómicas en España, por ejemplo la catalana, que ofrecen planteamientos y desarrollos de interés. Especial interés ofrecen los casos de las reformas realizadas en los países del Norte de Europa y especialmente en Alemania, dónde se ha conseguido reducir el número de los Entes locales a partir de estrategias públicas bien interesantes que conviene conocer, no sólo para aprender, sino para comprender mejor el sentido del éxito en las reformas administrativas, algo desde luego ignoto para muchos especialistas y estudiosos de la Administración pública en general. Como regla, deberíamos entrar que todas las cuestiones que afecten de manera relevante a los espacios locales cuenten con el concurso y participación de los vecinos, no sólo de sus representantes o gobernantes. Algo, ciertamente, olvidado en un momento en que relevantes y trascendentales políticas públicas que afectan a cuestiones vitales para la existencia de los hombres se adoptan sin contar con la opinión de la población. Al menos, en el ámbito local, la participación vecinal debiera ser una pieza maestra de cualquier solución que se adopte. De lo contrario seguiremos en planteamientos burocráticos en los que una serie de iluminados o elegidos por la tecnoestructura tengan la última palabra y decidan cuestiones que en cualquier democracia seria y madura se consultan con el pueblo en su conjunto.

En el caso español, la realidad local es la que es que todos conocemos. Despoblación, y consiguiente inframunicipalismo en los espacios rurales y superpoblación en los espacios urbanos, escasa natalidad, fórmulas organizativas bien rígidas, también para las grandes ciudades a pesar de las previsiones de la nueva Ley de modernización del gobierno local de 2003, bien reciente. La planta de los Entes locales, heredada de la tradición francesa, se aplica por igual a 
todos los Entes locales, ahora con algunas especialidades para los grandes Ayuntamientos. La estructura de gobierno y administración local deja mucho que desear y es menester diseñarla en función de la realidad y de las necesidades colectivas de los vecinos.

En España, la existencia de una panoplia de Entes públicos con competencias en el territorio: Estado, Comunidades Autónomas, Provincias, Islas, Municipios, Comarcas... plantea también, aprovechando la crisis económica en que estamos sumergidos, soluciones a una presión administrativa que elevan irracionalmente el gasto público, lo que lleva inevitablemente a una competencia entre Administraciones a veces propia de una novela surrealista. Es conveniente, desde nuestro punto de vista, una reforma institucional, reforma, insisto, que sólo será posible si previamente se diseña un mapa competencial realista y objetivo. A partir de él, el montaje institucional es más sencillo y coherente.

Los Entes locales en España, como señaló una temprana sentencia del Tribunal Constitucional sobre el tema, de 1981, son Entes públicos con una naturaleza bifronte o híbrida. En efecto, en lo que atiende a las bases o a la ordenación general de su régimen jurídico ES EL Estado quien tiene la competencia. Ahora bien, si se trata de la ordenación de asuntos sectoriales entonces es la Comunidad Autónoma quien dispone normativamente de estas materias. La ley de bases de 1985 está superada tal y como reconoce unánimemente la doctrina. Es momento, también, para elaborar una Ley de bases que permita una mayor flexibilidad a los Entes locales, al modo anglosajón o centroeuropeo, para diseñar esquemas de gobierno y gestión más CORDES con las necesidades colectivas de los vecinos.

Mientras que en Europa, el porcentaje de gasto público que administran los Entes locales es del orden del $24 \%$, en nuestro país es del $16 \%$. Otro dato para la reflexión: las Corporaciones locales españolas tienen un gasto sobre el producto interior bruto del $6 \%$ mientras que el conjunto de la Euro-zona se encuentra en el $10.1 \%$

En Galicia, los datos son los que son: 315 municipios, dos más que hace veinte años; más de 3.000 Parroquias, y la mitad de los núcleos de población de todo el Reino: 32.000. Del total de Ayuntamientos, 200, más de la mitad cuentan con apenas 2.000 o 3.000 habitantes. Tenemos un Ayuntamiento de menos de 500 habitantes y 16 con menos de 1.000 En estas condiciones, no es difícil colegir que las arcas locales, sobre todo en una época de aguda crisis como la que 


\section{Cadernos do Programa de Pós-Graduação em Direito/UFRGS}

http://seer.ufrgs.br/ppgdir - ISSN: 1678-5029 - E-ISSN: 2317-8558

\section{Volume VIII | Número 2 | Ano 2013}

sufrimos, no estén muy boyantes. Más bien, el gran problema del mundo local en España, y especialmente en Galicia, es que numerosos municipios, por su tamaño y capacidad de gestión, serán inviables sino se buscan soluciones que permitan superar estos problemas.

En el ámbito de Galicia, como en otras Comunidades, especialmente en Valencia, cuyo anteproyecto de ley del régimen local apuesta por los fenómenos de asociacionismo y las fusiones locales fomentándolos claramente, se ha abierto un debate acerca de cómo resolver este gran tema. Un debate en el que deben participar los políticos, los empresarios, los sindicatos, los usuarios, la universidad, los colegios profesionales y todas aquellas instituciones y corporaciones relacionadas con el ámbito local. Estas líneas se escriben desde la invitación de la Xunta de Galicia a pensar en libertad acerca de cuáles pueden ser algunas líneas que puedan desembocar en soluciones reales que permitan que los Entes locales sigan prestando servicios para la mejora de las condiciones de vida de los vecinos. Este es la clave, tener bien presente que las fórmulas que se puedan arbitrar no pueden dejar de espaldas a los vecinos, por muy bien diseñadas que estén o por muy bien que puedan encajar en el Ordenamiento Jurídico. Si no se tiene claro que los dueños de los intereses públicos locales son los vecinos, si no se es consciente de que los vecinos son los propietarios de las instituciones públicas locales, si los políticos no asumen que son delegados o representantes de los vecinos a quienes deben dar cuenta de sus decisiones permanentemente, entonces estaremos perdiendo una oportunidad magnífica para poner las bases de la solución del problema.

Estamos en el siglo XXI y así como no tiene sentido alguno, por ejemplo, seguir explicando en la Universidad las instituciones y categorías del Derecho Administrativos por los manuales de autores franceses tan relevantes como Cormenain o Laferriere, que editaron sus lecciones en la primera mitad del siglo XIX, así tampoco es lógico que la planta organizativa de los Entes locales siga teniendo una impronta pensada para otros tiempos, con otro modelo de Estado y en un ambiente político y social distinto. Por tanto, reconociendo como se reconoce la importancia del Derecho Francés en el nacimiento del moderno Derecho Administrativo, es lo cierto que a día de hoy, la centralidad de los derechos de los vecinos y sus razonables expectativas de mejores servicios han de presidir las soluciones a adoptar. Soluciones que demanda el tránsito del Estado burocrático al Estado social y democrático de Derecho y que deben alumbrar nuevas piezas normativas y nuevas posibilidades organizativas. Ahora, sin 
embargo, tenemos que operar con lo que hay, de ahí que lo más razonable y sensato sea tener en cuenta los medios disponibles y buscar la mejor solución posible.

\section{UNA APROXIMACIÓN MULTIDISCIPLINAR A LA REALIDAD LOCAL}

Las cuestiones que afectan a la realidad política y administrativa, especialmente las que se refieren al estudio de las Administraciones y Gobiernos locales han de afrontarse desde una perspectiva abierta, plural, complementaria. Todos los enfoques que tienen relación, directa o indirecta, con los espacios territoriales locales han de ser convocados a su estudio. Si así no se hace, si se invoca una pretendida orientación como única para el estudio, entonces aviados estamos. Tanto si se decide que el enfoque politológico como el jurídico, el histórico, el económico o el psicológico han de tener pretensión de pensamiento único, entonces el estudios será parcial y, además, probablemente será un análisis sesgado, insuficiente. Esto ha acontecido en muchas ocasiones, no me importa confesarlo, con la pretendida soberanía científica del Derecho Administrativo en relación con la Administración Pública. Sin embargo, tan perverso es la dictadura en esta materia del Derecho Administrativo como, por ejemplo, la dominación de la ciencia política.

Los Entes locales, como reza la Carta Europea de la Autonomía Local, son uno de los principales fundamentos de la democracia. No sólo porque son el primer espacio público, y por ende político, con el que se encuentran las personas, sino porque en las democracias los Entes locales tienen un obvio carácter representativo que no se puede obviar. Como dice la exposición de motivos de la ya vetusta ley de bases del régimen local de 1985, constituyen uno de los principales fundamentos del régimen democrático. Como ha señalado el profesor Meilán Gil, son la expresión de la convivencia social más próxima dentro del Estado (2009, 22). No los crea la Constitución precisamente porque a lo largo de los siglos, sin que sean necesariamente la encarnación de una institución tan antigua como el mismo ser humano, el espacio local ha sido, es y seguirá siendo, el primer ámbito de acercamiento de las personas a la dimensión pública. Es decir, la persona penetra en el espacio de la deliberación pública ordinariamente en el municipio. En este sentido, siempre se ha entendido que el tamaño de los municipios y su población son elementos muy importantes en orden a facilitar la participación vecinal. En municipios de varios 


\section{Cadernos do Programa de Pós-Graduação em Direito/UFRGS}

http://seer.ufrgs.br/ppgdir - ISSN: 1678-5029 - E-ISSN: 2317-8558

\section{Volume VIII | Número 2 | Ano 2013}

millones de personas, el grado real de participación es más bien bajo, creciendo en consecuencia la desafección y la distancia de los habitantes en relación con los asuntos públicos, y tantas veces con los propios representantes locales.

En la Constitución española de 1978, como es bien sabido, están reconocidos en el Título VIII como elementos integrantes del Estado y dotados de autonomía, para la gestión de sus intereses, al igual que las Comunidades Autónomas. Es verdad que las Comunidades Autónomas según el artículo 2 de la Constitución disponen de capacidad legislativa, la mayor expresión de la autonomía. Que, además, la utilización del término Administración local sea el elegido por el constituyente para el capítulo II del Título VIII de la Constitución no ayuda de demasiado. Ahora bien, como ha señalado Meilán Gil, el carácter representativo de los municipios, expresado claramente en el artículo 140 de la Constitución no deja lugar a dudas (2009, 24), como también abona la tesis de la naturaleza política, también administrativa, de los Entes locales, que la nota de la representatividad, de la elección, no figura, dice Meilán Gil, en el artículo 103 de la Constitución, que es el referido por antonomasia a la Administración pública. Se trata de gobiernos y administraciones locales, o por mejor decir, gobiernos locales, pues la denominación gobierno incluye en sí misma, la existencia de una Administración que actúa bajo la dirección del gobierno para el servicio objetivo del interés general.

En el Reino Unido, como sabemos, los llamados poderes locales están en la entraña misma de la democracia y son, desde luego, una de sus pilares más destacados. Junto a la institución democrática, la vitalidad de los poderes locales es fundamental, junto al Parlamento, para una vida democrática real. Como recuerda Meilán Gil, hay un dicho bien claro en la literatura sobre los poderes locales británicos que demuestra claramente este aserto central: si el self-government se marchita, las raíces de la democracia se secan $(2009,24)$

En realidad, la explicación de conformar a los Entes locales desde la perspectiva administrativa exclusivamente, como Administración local, hunde sus raíces en la ideología burguesa que conformó el quehacer público en la España del siglo XIX y que tanto influyó, aunque parezca sorprendente, en la perspectiva centralista, unilateral y anclada en el Estado de la misma concepción del Derecho Administrativo y de todas sus categorías e instituciones. Hoy, sin embargo, como ha ratificado el Tribunal Constitucional ya en su sentencia de 2 de febrero de 1981 son corporaciones locales de naturaleza representativo, y su gobierno y administración 


\section{Cadernos do Programa de Pós-Graduação em Direito/UFRGS}

http://seer.ufrgs.br/ppgdir - ISSN: 1678-5029 - E-ISSN: 2317-8558

\section{Volume VIII | Número 2 | Ano 2013}

tienen el carácter de autónomas para la gestión de sus respectivos intereses, lo que exige que se dote a cada Ente local de todas las competencias propias y exclusivas que sean necesarias para satisfacer el interés respectivo.

La autonomía local existe porque hay un determinado círculo de intereses públicos imbrincados sustancialmente con la dimensión local. El problema es que si bien la Constitución quiso establecer las materias de competencia de las Comunidades Autónomas y del Estado, en el caso de los Entes locales guardó silencio. Un silencio que demuestra de alguna manera que los constituyentes se concentraron especialmente en las Comunidades Autónomas y dejaron a los Entes locales bajo la disponibilidad normativa del Estado y de las propias Autonomías. Desde el principio el Tribunal Constitucional reconoció, desde esta perspectiva, la naturaleza bifronte de los Entes locales. Por una parte, es el Estado quien puede ordenar jurídicamente los asuntos centrales y medulares de la vida local. Y, por otra, son las Comunidades Autónomas, a través de sus correspondientes Parlamentos, las competentes para la ordenación sectorial de los Entes locales.

La Constitución reconoce que existen intereses locales, reconocimiento que debe ser garantizado. La técnica elegida, ahora un poco pasada de moda, fue la de la garantía institucional, de tradición germana. De esta manera, la actuación normativa del Estado y de las Comunidades Autónomas sobre los Entes locales, deben respetar la garantía institucional de la autonomía local, que se centra en los elementos esenciales o núcleo primario del autogobierno. La garantía institucional acogida tempranamente por la doctrina del Tribunal Constitucional por ejemplo, en la sentencia de 28 de julio de 1981, cuando afirma el alto Tribunal que la garantía institucional no garantiza un contenido concreto o un ámbito competencial determinado y fijado de una vez por todas, sino preservación de una institución en términos recognoscibles que para la imagen que de la misma tiene la conciencia social en cada tiempo y lugar.

En el caso del espacio local, hay gobierno, porque hay elecciones, y hay administración porque se toman decisiones políticas que precisan de implementación, como ahora se dice, administrativa, porque hace falta tarea de "servicio objetivo al interés general". Y, por supuesto, el enfoque económico y presupuestario es capital porque las políticas públicas locales han de estar soportadas en un presupuesto que tiene ingresos, procedentes de varias fuentes, y tiene gastos para atender el personal y las obras y servicios de interés vecinal. Es más, si las haciendas 


\section{Cadernos do Programa de Pós-Graduação em Direito/UFRGS}

http://seer.ufrgs.br/ppgdir - ISSN: 1678-5029 - E-ISSN: 2317-8558

\section{Volume VIII | Número 2 | Ano 2013}

locales no están saneadas, la autonomía local será una quimera y no se podrán prestar adecuadamente servicios a los vecinos.

También desde la realidad social se observa un fenómeno preocupante desde el punto de vista de la capacidad de gestión y de la suficiencia financiera de los Ayuntamientos. Me refiero a que en muchas ocasiones los Entes locales asumen competencias que no son propias, que se llaman impropias, que terminan por descuadrar los presupuestos a pesar de que se trata realmente de tareas que si no las realizan los Entes locales se quedan sin hacer. Esta realidad ha de tenerse presente en un futuro catálogo de competencias locales.

Años atrás, en 1999, el gobierno británico, entonces liderado por Blair, publicó un libro blanco sobre la reforma administrativa bajo el mandato del ministro Cunningham, que llevaba como rótulo: la Administración pública una tarea para la mejora de las condiciones de vida de los ciudadanos. Pues bien, para que las Administraciones y Gobiernos locales puedan contribuir decisivamente a la mejora de las condiciones de vida de los vecinos es obvio que han de poder organizarse, en el marco de unas bases generales amplias, de la forma que entiendan más eficaces y eficientes. Este es un punto muy relevante porque imponer un modelo organizativo único para todos los casos, sea cual es el tamaño y la dimensión del Ente local, resulta algo anacrónico en los tiempos en que vivimos en los que, insisto, el modelo de Estado burocrático ha sido abandonado por un modelo de Estado humano, a escala humana, con estructuras e instituciones territoriales, entre ellas las locales, dedicadas a contribuir a la mejora de las condiciones de vida de los vecinos.

De la ciencia política, nos interesan sobremanera las consideraciones sobre la definición, ejecución, y evaluación de políticas públicas locales y, sobre todo, las políticas de participación vecinal, de forma y manera que la opinión de los vecinos tenga el peso que debe tener, por ejemplo, en los procesos de fusión municipal. Las explicaciones sobre la forma de prestar los servicios locales de manera más eficaz y eficiente, las cuestiones sobre las tripas de la gestión local o sobre el manejo y conducción de determinados intereses públicos locales también competen a la ciencia política y de la administración y son relevantes para el análisis de la situación de los Entes locales en España y en Galicia. 


\section{Cadernos do Programa de Pós-Graduação em Direito/UFRGS}

http://seer.ufrgs.br/ppgdir - ISSN: 1678-5029 - E-ISSN: 2317-8558

\section{Volume VIII | Número 2 | Ano 2013}

Los aspectos financieros son básicos. Las políticas públicas locales, consecuencia de las competencias de que disponen los Entes locales según el esquema de atribuciones dibujado en el bloque de constitucionalidad, sólo serán posibles si los Gobiernos y Administraciones locales tienen fondos para afrontar tales responsabilidades. Y hoy, tras más de treinta años de andadura constitucional, es lo cierto que la suficiencia financiera de estos Entes de los que tanto se espera y en lo que tanto se confía, no es más que una quimera. Por eso, la financiación local es una cuestión indisolublemente unida al un nuevo esquema organizativo en el mundo local puesto que sin fondos no hay autonomía posible, no hay autonomía real. La autonomía en estos casos, bien lo saben los alcaldes y concejales, no es más que pura retórica.

Como es bien sabido, la historia ofrece siempre perspectivas iluminadoras de la realidad porque ayuda sobremanera a comprender las causas y el sentido que tienen en el presente las instituciones objeto de estudio o análisis. En el campo de los Entes locales, no es ningún secreto afirmar que en efecto el mapa local española es manifestación del espíritu ilustrado que presidió las Cortes de Cádiz de 1812. En virtud de la lógica racionalista del momento y del protagonismo de la institución estatal como paladín y solución de todos los males y transmisor de todos los bienes, la benemérita Constitución de Cádiz de 1812 dispone que se constituya en cada pueblo de al menos mil habitantes un Ayuntamiento. Más adelante, por mor de un Real Decreto de 1835 los Ayuntamientos verán ampliado su territorio con la incorporación de parroquias vecinas hasta alcanzar la nada desdeñable cifra de 11.271 municipios, muy superior a la actual, lo que quiere decir que en algún momento se procedió a racionalizar un mapa de estructuras locales demasiado elevado. Las leyes de 1856, 1870 y 1877 vincularon la dimensión territorial del Ayuntamiento con la capacidad para gestionar y administrar las competencias atribuidas, estableciéndose como parámetros básicos para que un Ayuntamiento viniera al mundo: contar con no menos de 2.000 habitantes residentes y capacidad para atender los gastos municipales con los recursos autorizados por las leyes de entonces. Recordemos que hoy hay en España, y también en Galicia, reino donde los haya de inframunicipalismo, hay Concellos de menos de 2.000 habitantes.

Es bien conocida la óptica profundamente racionalizadora desde la que se elaboraron las bases para la Ley Orgánica Municipal de 1906, entre las que se exigía una población no menor de 2000 habitantes para ser considerado Ayuntamiento. Los municipios que no contaran con esta población habrían de ser incorporados a los más próximos prohibiéndose la constitución de 


\section{Cadernos do Programa de Pós-Graduação em Direito/UFRGS}

http://seer.ufrgs.br/ppgdir - ISSN: 1678-5029 - E-ISSN: 2317-8558

\section{Volume VIII | Número 2 | Ano 2013}

nuevos Entes locales con una oblación menor a la referida. El tamaño, pues, de los Entes locales, estuvo muy presente en los legisladores y gobiernos del siglo XIX y del XX hasta el punto de propiciarse, a principios del siglo XX operaciones de incorporación para disponer de Entes locales con capacidad suficiente para prestar los servicios a la medida de los vecinos. Esta es la cuestión: Entes locales con medios suficientes para gestionar las competencias en un marco de mejora de las condiciones de vida de los habitantes. Incluso durante la etapa política anterior a la actual, los Gobernadores civiles podían, bajo los auspicios de la todopoderosa dirección general de Administración local, proceder a operaciones de fusión o incorporación para que los Entes locales tuvieran el tamaño y los medios adecuados para atender razonablemente a los vecinos. En 1966, una modificación parcial de la Ley de Régimen local constituyó un Fondo Nacional de la Hacienda Municipal con el propósito de, entre otros, de estimular económicamente las agrupaciones municipales a efectos del sostenimiento económico del servicio o una ulterior racionalización de la organización territorial. Ya por entonces se tomó conciencia, desde el centralismo imperante, de la necesidad de proceder a una reforma de la organización territorial de base local. Otra norma destacable en este proceso racionalizador es el Real Decreto 3.046/1977 por el que se estableció la agrupación forzosa de los municipios de menos de 5000 habitantes para el sostenimiento de la secretaría municipal y en su caso de personal común cuando la población no alcanzaba los 2.000 habitantes, algo que a día de hoy se produce, al menos que yo sepa en el ámbito de las secretarías, gracias al apoyo técnico que ofrece para estos supuestos la Diputación provincial.

Con el advenimiento del régimen constitucional, las competencias para la alteración, según el artículo 148.1.2 $\mathrm{CE}$, corresponde a la Comunidad Autónoma, que tiene las facultades para diseñar una estructuración del mundo local que, coherente con las bases estatales, puede realmente racionalizar y modernizar unos Entes públicos territoriales hoy en muchos casos sin medios, sin personal, sin capacidad real de incidir positivamente en la vida de los vecinos. La ley de bases del régimen local de 1985 atribuyó al Estado la posibilidad de adoptar medidas de fomento para las fusiones municipales. Veamos el resultado brevemente en los últimos cincuenta años más o menos.

Se calcula que entre 1960 y 1980, con estas medidas racionalizadoras, desaparecieron 1.263 municipios, mientras que se constituyeron, con los nuevos criterios, 103: 13 por 
segregación 90 por fusión. Por tanto, precedentes en España los hay. En los países del Norte de Europa, especialmente en Alemania, en la década de los sesenta del siglo pasado, se pusieron en marcha una serie de medidas orientadas a racionalizar el mapa local que dieron bastante resultado con un relativo coste para los políticos y reformadores.

Hoy contamos con 8.112 Ayuntamientos. En 1981 había 8.022, luego hemos crecido. En Galicia, de 313 en 1990, ahora tenemos 315. Este es el drama, que sabemos que hay que racionalizar pero caemos presos de la irracionalidad política, tantas veces a causa de tolerar y permitir que sean los políticos locales los dueños y señores de un mundo en el que los vecinos deberían participar más activamente y desde las instancias autonómica y nacional, proceder a lanzar más mensajes racionalizadores. En efecto, entre 981 y 1991 desparecieron 12 Ayuntamientos y se crearon 67: 2 por fusión y 65 por segregación. Entre 1991 y 2001 todavía seguimos creciendo, aunque a un ritmo menor: se crearon 10 municipios, llegándose, repito a 2008 con 8.112 municipios, más de los que había en 1981. Es verdad que hoy hay menos que en 1812, pero también es verdad que hoy las cosas son distintas y que hoy las potencialidades de los Entes locales no tienen comparación alguna con las posibilidades de entonces de los más de 11.000 Ayuntamientos.

Desde el punto de vista de la fenomenología actual, hay que tener presente que la tendencia que se aprecia en todo el mundo acerca del asentamiento de las poblaciones refleja un claro predominio de las Áreas metropolitanas. En general, la corriente circula en dirección a los fenómenos de integración, de asociación, siendo capaz más escasos los procesos de segregación o aislamiento. Desde el campo de la Hacienda pública, los fenómenos de colaboración suelen denominarse: fusión, asociación y aglomeración. La profesora Cadaval Sampedro ha estudiado esta cuestión desde la perspectiva de la Hacienda pública $(2001,8)$. Por lo que se refiere a la fusión, reunir sobre un mismo territorio administrativo, financiero y político a varios Entes locales que asumen diversas funciones en un área determinada, hay argumentos de diversa naturaleza. Cadaval Sampedro $(2001,8)$ entiende que la fusión permite una mayor eficacia en la provisión de bienes y servicios públicos, economías de escala, incremento en la calidad de las prestaciones, reducción de los costes así como una mejor internalización de los efectos desbordamiento. Por otra parte, la fusión facilita que los el nuevo Ente local tenga una mayor posición institucional para negociar de forma efectiva con otras instancias de gobierno superior al 


\section{Cadernos do Programa de Pós-Graduação em Direito/UFRGS}

http://seer.ufrgs.br/ppgdir - ISSN: 1678-5029 - E-ISSN: 2317-8558

\section{Volume VIII | Número 2 | Ano 2013}

aumentar la autonomía perceptible y mejorar el sistema de perecuación financiera. Otra ventaja que señala Cadaval Sampedro $(2001,8)$ se refiere a que la fusión municipal permite desarrollar capacidades relacionadas con el capital humano y los medios financieros que no serían posibles anteriormente, posibilitando la puesta en valor de las potencialidades del territorio a través, por ejemplo, de la creación de polígonos industriales, recalificación de usos del suelo, canalización de suministros o mejora de las comunicaciones.

Sin embargo, no todo son ventajas en estos casos de fusiones de municipios desde la óptica de la Hacienda pública. La profesora Cadaval Sampedro señala también algunos problemas que debemos registrar: la fusión no resuelve todos los problemas de inadaptación del territorio: algunos se mitigarían pero otros subsistirían. Es decir, podría ocurrir que se interiorizaran todos los efectos externos, se aprovechasen las economías de escala y se redujesen los costes de congestión, sin asegurar que esto sea así para todos los bienes públicos locales. La situación es más complicada en las denominadas fusiones mayores, donde es prácticamente imposible encajar los territorios funcional, institucional y relacional para todas y cada una de las funciones del sector público local (Cadaval Sampedro, 2001, 9). Además, cuanto mayor es el Ente público, normalmente mayores son los problemas burocráticos aumentando la ineficacia. Según parece, la fusión con el tiempo distancia a los vecinos de los problemas reales generando una cierta dejadez a la hora del ejercicio del derecho democrático del voto. Como apunta la profesora Cadaval Sampedro $(2001,9)$, la desaparición de un número de municipios elegidos de manera democrática hace susceptible el incremento de la distancia entre los ciudadanos y sus representantes. Las fusiones encuentran resistencia, fundamentalmente, en las circunscripciones más pequeñas, al considerar que todo el poder se centrará en la ciudad mayor, la que impondrá sus preferencias sobre todos los demás, privándoles de participar en las decisiones que les atañen.

\section{PANORAMA GENERAL Y PARTICULAR}

En el ámbito de la Unión Europea se considera que el umbral mínimo para un municipio viable, aquel que puede operar en un marco de suficiencia financiera, política y técnica, se cifra en 5.000 habitantes. Pues bien, Galicia, como ha señalado un interesante Informe del Círculo de Empresarios de Galicia, tiene un registro difícil de superar: el 63.2\% de nuestros Ayuntamientos, 


\section{Cadernos do Programa de Pós-Graduação em Direito/UFRGS}

http://seer.ufrgs.br/ppgdir - ISSN: 1678-5029 - E-ISSN: 2317-8558

\section{Volume VIII | Número 2 | Ano 2013}

199, tenían en 2008 una población inferior a los 5.000 habitantes $(2009,11)$. Tenemos un Ayuntamiento de menos de 500 habitantes y 16 con menos de 1000. Es decir, la mayoría de nuestros Ayuntamientos, según estos registros de la Unión Europea tienen dificultades para prestar servicios con la calidad, eficacia y eficiencia exigibles en un moderno Estado social y democrático de Derecho. Porque no se trata, simplemente, de prestar servicios como sea. Se trata de adecuar las estructuras políticas y administrativas a las necesidades colectivas de los habitantes. Si así no fuera, estaríamos instalados en un grave problema porque entonces las instituciones y las entidades públicas serían fines en sí mismos, normalmente al servicio de unos dirigentes para quienes lo realmente determinante no es tanto atender cada mejor al pueblo, a los vecinos, sino mantenerse como sea en el poder.

Por si fuera poco, tenemos unas 3.000 parroquias y cerca de 32.000 núcleos de población. La despoblación de las zonas rurales y su concentración en las áreas urbanas también caracteriza el panorama gallego. El proceso de modernización operado en la segunda mitad del siglo pasado también dejó su huella en nuestra Comunidad Autónoma, de manera que la creciente urbanización producida en esos años facilitó, como señala el informe del Círculo de Empresarios de Galicia, un acceso generalizado a bienes y servicios avanzado, especialmente en materia de salud, educación y comunicación. En opinión del Círculo de Empresario de Galicia, “ el ingreso de España en la UE acentuó la urgencia de una ordenación del territorio que atienda a esa nueva realidad urbana. Porque solo desde una articulación eficiente de los diferentes núcleos de población en torno a grandes polos urbanos-metropolitanos tendrá acceso toda la población a los servicios del Estado de bienestar y a actividades y empleos con futuro"( 2009, 12). En este marco, los pequeños Ayuntamientos se han ido quedando aislados mientras crece la mayoría de edad de los vecinos y son mayores los problemas para el acceso a las nuevas tecnologías y a las nuevas oportunidades $(2009,11)$.

Es fácil de comprender que los Ayuntamientos con menor población tienen más dificultades ordinariamente para prestar los servicios que los habitados por cientos de miles de personas. Tal y como señala el informe que comentamos, la razón es bien sencilla: los Ayuntamientos con menor población tendrían que asumir proporcionalmente y por habitante mayor gasto que los Ayuntamientos más grandes para prestar los servicios mínimos que establece la ley de bases del régimen local de 1985. 


\section{Cadernos do Programa de Pós-Graduação em Direito/UFRGS}

http://seer.ufrgs.br/ppgdir - ISSN: 1678-5029 - E-ISSN: 2317-8558

\section{Volume VIII | Número 2 | Ano 2013}

Una buena ocasión para afrontar un proceso gradual de asociacionismo e integración de Entes locales lo ofrece la aguda crisis económica y financiera que también afecta, es obvio, a los Entes locales. Primero porque el problema de la financiación local lleva demasiado pendiente por atender preferentemente a las Haciendas de las Comunidades Autónomas. Y segundo porque la situación de crisis económica y financiera actual facilita enormemente las cosas. La necesidad de optimizar los recursos, de racionalizar los gastos, es a día de día una urgencia obvia entre nosotros. Reflexiones y comentarios como el de que hay que gastar menos, que hay que gastar mejor con menos, se suceden en este tiempo entre los responsables de las arcas públicas de la dimensión territorial que sean. Como señala el Círculo de Empresarios de Galicia en su informe, “ aplicar economías de escala derivadas de de la reducción-agrupación-optimización de las Administraciones locales, y del incremento de eficacia y de eficiencia, y conjugar todo ello con la adecuación de los servicios a las necesidades reales de los ciudadanos, pueden ser algunas de las medidas que nos permitan alcanzar la inevitable austeridad en el gasto público sin que esto afecte a los servicios que recibe la población; más bien, al contrario, al menos en lo que se refiere a esos pequeños municipios que, hoy por hoy, tienen enormes dificultades para prestar esos servicios con la calidad exigible" $(2009,12)$.

Varias cuestiones me llaman poderosamente la atención del informe del Círculo de Empresarios de Galicia: la necesidad de pensar cómo prestar mejor los servicios en las áreas metropolitanas, la adecuación de los servicios a las necesidades reales de los vecinos y, sobre todo, la caracterización del gasto público de austero. Veamos. Es verdad que en las zonas de creciente urbanización han ido surgiendo, junto a las grandes ciudades, áreas urbanas que aunque no integradas formalmente en ellas, constituyen una mera prolongación. Estos ciento de miles de habitantes no pueden estar discriminados en los servicios a recibir solamente por fijar su residencia en uno u otro municipio. Más grave es, desde luego, la cuestión de la naturaleza y necesidad de los servicios y actividades que realizan los Entes locales. Por una razón bien sencilla: no siempre se tiene en cuenta la opinión de los vecinos a la hora de establecer un determinado servicio o realizar una concreta actividad porque tales políticas obedecen a necesidades de personal de los propios concejales o de las personas que les han votado esperando a cambio, como si estuviéramos en el tradicional sistema del botín, sr colocados a costa del presupuesto público. Por lo que se refiere que el gasto público sea austero en todo momento y circunstancia, no sólo en época de crisis, es algo asumido en la doctrina científica. La 
Constitución en su artículo 31, ya lo hemos dicho, señala que la programación del gasto público ha de realizarse con arreglo a parámetros de economía y eficiencia.

Es bien sabido, y no por ello conviene olvidarlo, que en Galicia los Ayuntamientos se formaron a partir de las parroquias, compuestas de aldeas y lugares, en torno a una cabeza municipal. Galicia contaba en 1836 con 347 Ayuntamientos, más o menos lo que tenemos en la actualidad. Sin embargo, al contrario de lo que ocurrió en otras partes de España, la identidad propia de la persona no era tanto con el Ayuntamiento como con la parroquia, con la aldea, algo que está todavía vigente entre nosotros y que explica la fuerte vinculación, sobre todo con la aldea, que se encuentra en tantos y tantos gallegos. De ahí que el propio Estatuto de Autonomía, aunque dejando la cuestión abierta, reconociera nada menos que personalidad jurídica a la parroquia.

En 1918, como recuerda el informe del Círculo de los Empresarios de Galicia, descendió considerablemente el número de municipios. Pasamos de 347 en 1836 a 322 en 1918, ninguno con menos de 1.000 habitantes. En este período de tiempo disminuyó el número de municipios considerablemente. ¿Qué ocurrió entonces?. Pues que se acometieron procesos de fusión municipal, algo que ya tienen precedentes entre nosotros y que, como veremos al analizar brevemente algunas experiencias comparadas, ha caracterizado los procesos de reorganización municipal en Alemania y en los países del Norte de Europa en la década de los sesenta y setenta del siglo pasado. Tal y como recuerda el informe del Círculo de Empresario, las últimas fusiones se produjeron en 1962, cuando Enfesta se incorporó a Santiago de Compostela; en 1963, cuándo Vilameá y Vilaodriz se convirtieron en A Pontenova, en la provincia de Lugo; en 1967 Acevedo pasó a Celanova (Ourense). Sin embargo, desde la promulgación del Estatuto de Autonomía, las cosas han tomado derroteros bien distintos: de 314 Ayuntamientos en esa fecha hemos pasado a día de hoy, tras las segregaciones de Cariño de Ortigueira en 1988, Burela de Cervo en 1994y A Illa de Vilanova de Arousa en 1997, a 315. Esta es la realidad.

Así las cosas, la cuestión del tamaño y población de los Ayuntamientos en Galicia es un asunto presente en los discursos de todos los partidos políticos en la actualidad, sobre todo después que la actual Xunta de Galicia haya manifestado su voluntad política de proceder a un proceso de fusiones y concentraciones municipales $\mathrm{y}$, en general, de asociacionismo y colaboración intermunicipal. En realidad, el asunto del tamaño no es lo prioritario: lo central es si 
con la dimensión que tienen permite o no atender a los vecinos como exige un Estado social y democrático de Derecho. Este es el punto capital: si los poderes públicos locales mejoran o no cada día las condiciones de vida de los vecinos.

Cómo es sabido, durante la presidencia de Fraga Iribarne se puso un marcha un proceso de comarcalización orientado a hacer de las comarcas espacios de planificación y desarrollo económico y social, sin constituir como Entes locales estas demarcaciones territoriales. Sin embargo, tras relevantes estudios de la realidad comarcal gallega desde diferentes puntos de vista, el gobierno bipartito no participó de esta estrategia y, al cabo del tiempo, abandonó esta política de desarrollo territorial que sirvió para conocer mejor las necesidades colectivas de las comarcas. Hoy, en la ley de Administración local de Galicia de 1995 se establece como población mínima para la constitución de un nuevo Ayuntamiento 5.000 habitantes, señalando que el procedimiento para llevar a cabo fusiones municipales puede ser iniciado de oficio por la consellería competente o a instancias de los municipios afectados o de las propias diputaciones provinciales, disponiéndose que en caso de iniciarse de oficio con oposición de alguno o algunos municipios, que tal reorganización territorial sea aprobada por el Parlamento de Galicia.

La dispersión de la población gallega es un problema relevante. La dispersión implica un mayor coste para la creación de infraestructuras y para la prestación de los servicios. Por otra parte, el envejecimiento de la población, especialmente en los pequeños municipios a causa de la dispersión poblacional, es otro grave problema pues la previsión es poco halagueña.

La dispersión, sin embargo, no es privativa de Galicia. En efecto, la despoblación, el éxodo rural, el envejecimiento demográfico y la desaparición de municipios por quedarse sin habitantes es una realidad en algunas partes de España. Sin ir más lejos, la provincia de Huesca ha perdido 29 pueblos en 10 años: desde el 2000 a nuestros días la provincia de Huesca, por despoblación, ha perdido 31 municipios en la zona pirinaica especialmente. En términos generales, en España han desparecido 900 pueblos en los últimos quince años, sobre todo en Asturias y en Galicia. Por provincias, el caso de Lugo es particularmente significativo porque una de cada 4 poblaciones deshabitadas en los últimos 15 años era lucense. En nuestra Comunidad Autónoma, 75 municipios han perdido la mitad de su censo en los últimos 40 años. En efecto, 75 Ayuntamientos gallegos han perdido desde 1970 más de la mitad de su población, con las dramáticas consecuencias que de ello se deriva. Aquí, en Galicia, el éxodo rural se produjo más 


\section{Cadernos do Programa de Pós-Graduação em Direito/UFRGS}

http://seer.ufrgs.br/ppgdir - ISSN: 1678-5029 - E-ISSN: 2317-8558

\section{Volume VIII | Número 2 | Ano 2013}

tarde que en otras zonas de España y, unido al problema de la baja natalidad, configura un nuevo reparto poblacional del que han salido beneficiadas indiscutiblemente las ciudades y sus áreas de influencia llevándose la peor parte los municipios rurales, especialmente los de las provincias interiores de Lugo y Ourense.

Más adelante comentaremos algunas experiencias europeas, especialmente la de Alemania para reorganizar el mapa territorial. En este punto interesa, sin embargo, llamar la atención acerca de que es posible emprender políticas dirigidas a paliar las negativas consecuencias de esta situación en Galicia. En Europa, en la década de los sesenta y setenta del siglo pasado se emprendieron, con éxito, procesos de reorganización territorial. Es verdad que en algunos casos fue el poder político el que tomó directamente las riendas del proceso, en ocasiones sin contar con los propios vecinos, más preocupados de mantener a capa y espada unas identidades que los sumirían en la pobreza y la marginalidad.

Las Haciendas locales, es bien sabido, están en una situación dramática. De hecho no contamos con un modelo de financiación local razonable puesto que primero se ha atendido a resolver, no siempre con rigor y eficacia, la financiación de las Comunidades Autónomas. Por lo que se refiere al ámbito de la Comunidad Autónoma de Galicia, la viabilidad y solvencia de determinadas Entidades locales, Diputaciones y Ayuntamientos, es cuestionada. En efecto, el Consello de Contas de Galicia en su último informe publicado llama la atención de que los Entes locales gallegos disponen de los ingresos por habitante más bajos de España, alcanzando el 65.93 $\%$ de la media de los Ayuntamientos españoles. Como refleja el informe del Círculo de Empresarios de Galicia, Galicia está a la cola de España en lo que a ingresos tributarios locales se refiere, ascendiendo al $68 \%$ de la media del conjunto nacional. La media de este concepto está en 345,08 euros por habitante. Mientras que las ciudades gallegas de más de 50.000 están en 502,12 euros per cápita, los Ayuntamientos de menos de 5.000 habitantes están en 195,26 euros ( 2009, 21).

Al tratar del pacto local, de la segunda descentralización, sigue siendo una reclamación permanente de las asociaciones de Entes locales el derecho de estas Corporaciones a recibir las transferencias necesarias para atender las competencias que les son propias. A este problema de insuficiencia financiera ordinaria se suma la cuestión relativa a competencias que se prestan a iniciativa de las Comunidades Autónomas en virtud de determinadas subvenciones que, cuando 
desaparece la subvención, es francamente difícil explicar a los vecinos que a partir de entonces se quedarán sin tales o cuales actividades o servicios prestados por mor de dichas competencias.

En sede de Haciendas locales siempre conviene recordar el principio de suficiencia financiera de los Entes locales establecido nada menos que en el artículo 142 de la Constitución. Suficiencia que parte de los ingresos tributarios locales y de la participación en los ingresos del Estado y de las Comunidades Autónomas. En esta materia, hay que recordar que los baremos establecidos para esta participación acusan, dice el informe del Círculo de Empresarios de Galicia, la enorme fragmentación municipal, que repercute en el sobredimensionamiento del gasto público, restando eficacia y eficiencia a la gestión municipal. Se priman criterios como la población, el esfuerzo fiscal y el inverso de la carga tributaria. Sobre todo se valora la población, de manera que siempre los Entes locales más poblados son los que reciben más fondos por esta vía. Es más, el 75 \% del reparto de los ingresos del Estado se realiza en función de la población de derecho municipal, a la que se aplican tres coeficientes multiplicadores: 1, para los municipios de menos de 5.000 habitantes, 1,7 en el caso de Ayuntamientos con una población comprendida entre los 5001 y los 20.000, 1.3 para poblaciones de 20.001 a 50.000. Los pequeños municipios están claramente penalizados por este concepto. El 25\% restante de reparto de estos ingresos se valora, por partes iguales, en función del esfuerzo fiscal y el inverso de la carga tributaria (2009, 22-23).

El artículo 142 de la Constitución también habla de la participación en los ingresos de las Comunidades Autónomas. Sin embargo, esta previsión constitucional está prácticamente inédita y sin desarrollar sistemáticamente. Claro que hay fondos autonómicos para atender a necesidades de financiación local, pero lo que plantea la Constitución es que se articule un sistema para que tal precepto se pueda cumplir.

En este contexto, el 63,2\% de los municipios gallegos, que son los que tienen menos de 5.000 habitantes, se calcula que para 2025 ascienda al 65,7 \%. De esta forma, estos Entes locales, vía participación en los ingresos del Estado recibirán un $40 \%$ menos de lo que reciben por habitante los municipios que superan los 50.000 habitantes, un $30 \%$ menos de los de 20.001 a 50.000 , y un $17 \%$ menos que los comprendidos entre 5.001 y 10.000 vecinos (Informe del Círculo de Empresarios gallegos, 2009, 23) 


\section{Cadernos do Programa de Pós-Graduação em Direito/UFRGS}

http://seer.ufrgs.br/ppgdir - ISSN: 1678-5029 - E-ISSN: 2317-8558

\section{Volume VIII | Número 2 | Ano 2013}

El nivel de gasto público de los Entes locales oscila entre el 13 y el $16 \%$ según cuál sea la estadística que se maneje. En todo caso, estamos muy lejos de $56 \%$ de los daneses, del $27 \%$ de los italianos o del $18 \%$ de los franceses. La cuestión local en España es bien compleja: prestan un gran número de servicios y realizan actividades vinculadas a los intereses públicos con gran intensidad. Sin embargo, tienen un peso en el gasto público general que claramente no es acorde con las competencias ejercidas.

En este contexto, es razonable que, en Galicia u otras partes de España, Castilla-León o Valencia entre otras, se planteen políticas de fusión municipal en el marco de procesos de asociacionismo e integración municipal. Los números cantan y la necesidad de prestar servicios a los vecinos, no de cualquier manera, sino de forma que contribuyan a mejorar sus condiciones de vida, aconsejan tomar decisiones en esta dirección. Por se entiende bien que el propio Círculo de Empresarios de Galicia acabe de reclamar que se pongan en marcha fusiones de pequeños Entes locales y que se regulen las áreas metropolitanas.

En efecto, los procesos de asociacionismo voluntario vía mancomunidades y consorcios intentan resolver el problema. En Galicia en 2006 existían 24 mancomunidades de municipios y 27 consorcios locales. La percepción de estas fórmulas de colaboración es positiva. El problema es que tales instituciones, que bien podrían generar economías de escala, normalmente no la producen porque no se elimina los órganos que con anterioridad se encargaban de prestar los servicios que ahora se prestan vía mancomunidad o vía concierto. Las comarcas no se han constituido como Entes locales y ahora la comarcalización está en dique seco. Las áreas metropolitanas tampoco se llegaron a conformar normativamente.

El gran problema es que de seguir las cosas como hasta ahora empezarán a desaparecer municipios por falta de población y los más pequeños que sobrevivan, que en Galicia tienden a crecer van a tener infinitos problemas de financiación, sobre todo en lo que concierne a los servicios más básicos para los vecinos. La razón invita, pues a reorganizar municipios para prestar mejor los servicios. El principal problema es que muchos se aferran, a veces por interés de los políticos, a su identidad propia y al temor a desaparecer. El informe Roca, que aconsejó la fusión de los municipios catalanes de menos de 250 habitantes, tuvo una reacción visceral de los pequeños municipios. No hay que olvidarlo. No sólo fue el detonante de la posición de los pequeños municipios el miedo a la desaparición. La pérdida de representatividad política, como 
recuerda el informe del Círculo de Empresarios de Galicia, también explica la reacción de los pequeños municipios: el $70 \%$ de los concejales españoles pertenecen a municipios de menos de 5.000 habitantes.

\section{ALTERACIONES TERRITORIALES: FUSIONES E INCORPORACIONES}

En España el Ordenamiento jurídico distingue diversas fórmulas para propiciar horizontes o espacios de asociacionismo municipal: fusiones, incorporaciones, mancomunidades, comarcas, consorcios o áreas metropolitanas entre otros. Es claro que los fenómenos de segregación, de división de municipios no interesan porque agravarían más el problema de los pequeños municipios. Otra cosa sería si la realidad fuera de municipios demasiado grandes, como pasa por ejemplo en Iberoamérica, y para fomentar la participación vecinal fuera menester dividir algunos grandes municipios. En este caso operamos sobre la realidad española, singularmente sobre la gallega que es la que es y todos conocemos bien.

En el Texto refundido de disposiciones vigentes en materia de régimen local se establece en el artículo 3, 1 igual que el artículo 2 del Reglamento de población, que las alteraciones de los términos municipales pueden producirse por fusión, por incorporación o por segregación de parte de un municipio para agregarlo a otro limítrofe, y por segregación de parte del territorio de uno o varios municipios para formar otro independiente.

Es bien sabido que de acuerdo con lo dispuesto en la legislación del Estado en la materia, las alteraciones de los términos municipales no pueden no pueden generar enclaves nuevos. Además, la alteración de los términos municipales tampoco puede modificar los límites provinciales tal y como dispone el artículo 3.2 del Texto refundido. El artículo 13.2 de la ley de bases del régimen local dispone una serie de requisitos sustanciales para que puedan operarse procesos de alteración de los términos municipales. En los casos de segregación es necesario que se trate de núcleos territorialmente diferenciados, que los municipios resultantes tengan los recursos suficientes para prestar los servicios mínimos, y que ello no implique un empeoramiento de la calidad de los servicios prestados. En los casos de fusión o incorporación, como veremos, 
las cosas discurren por otros derroteros exigiéndose, como es lógico, que el municipio resultante de la operación esté en mejores condiciones de prestar los servicios a los vecinos.

La ley de bases del régimen local, consciente del problema general de España en la materia, dispuso acertadamente que el Estado pueda adoptar medidas de fomento para la fusión de municipios con la idea de salir al paso de la problemática de tantos pequeños municipios con dificultades reales para prestar adecuadamente los servicios mínimos a los vecinos.

Las alteraciones territoriales plantean un importante problema desde la consideración de su lesión, o no, del principio de la autonomía local. La profesora Escuín Palop ha estudiado esta cuestión en su proyección histórica (2003, 1269). Veamos brevemente su interesante argumentación. El municipio según la ilustración francesa, entendido como una comunidad de vecinos regida por sus representantes y cuya esfera de actuación se circunscribe a la satisfacción de los asuntos locales trae consigo dos relevantes consideraciones: extensión de la institución municipal a todas las comunidades de vecinos desde una perspectiva de igualdad formal, y uniformidad de su régimen jurídico. Consecuencias que salen al paso de lo acontecido en la Edad Media, dónde los municipios disponían de toda una serie de privilegios y singularidades frente al poder del monarca. El Estado liberal trata de suprimir todos estos privilegios a base de diseñar un régimen igual para todos los municipios, sometiendo los Entes locales sin excepción al poder central a base de un régimen jurídico unitario e igual para todos. El advenimiento de los Borbones en España, con Felipe V a la cabeza, supone un intento de generalización del municipio castellano, aunque, como es bien sabido, ya desde entonces Navarra, Gupúzcoa y Vizcaya conservaron sus instituciones tradicionales de virreinato, corregidor regio y diputación.

Más adelante, como señala Escuín Palop, esta versión homogeneizadora y uniforme del régimen local es sustituida por la doctrina de la perspectiva iusnaturalista del municipio enraizada en la interpretación idealista del autogobierno local anglosajón que entre nosotros defendieron nada menos que Oliván u Ortiz de Zúñiga. Desde este punto de vista, el municipio era anterior al Estado y está compuesto por un conjunto de competencias indisolublemente vinculadas y emanadas de las necesidades colectivas de naturaleza local. Esta concepción del municipio, estático e inmovilista, implica un profundo respeto al municipio y a su dimensión territorial de manera que las posibilidades de reorganización territorial de los municipios desde el poder central tendrán escasas opciones de prosperar (Escuín Palop, 2003, 1270-1271). 


\section{Cadernos do Programa de Pós-Graduação em Direito/UFRGS}

http://seer.ufrgs.br/ppgdir - ISSN: 1678-5029 - E-ISSN: 2317-8558

En cambio, desde la posición ilustrada, municipios como prolongación del poder central, municipios como apéndices del poder central para llegar al último rincón de la nación, las alteraciones territoriales fueron posibles puesto que su régimen jurídico era de libre disposición para el legislador. Ya sabemos que nuestra Constitución parte de este punto de vista al disponer que en su artículo 140 que la garantía de la autonomía local, una autonomía que se ha entendido, sobre todo en los primeros momentos, protegida por la técnica alemana de la garantía institucional, que aplicada a la autonomía local, parece referirse a la misma entraña del autogobierno y de la naturaleza representativa del mismo municipio, sin que se refiera al territorio porque lo relevante es que a través del carácter representativo, cauce inmediato de de participación ciudadana en los asuntos públicos, como dice el artículo 1.1 de la ley de bases de 1985, se presten los servicios públicos necesarios para la satisfacción de los intereses y necesidades de la Entidad local portadora de autonomía. En efecto, los fenómenos de alteración territorial del término municipal no se oponen a la autonomía local, aún incluso en contra de la voluntad de las propias Corporaciones. (Escuín Palop, 2003, 1271). Este argumento demuestra hasta qué punto los Entes locales son partes integrantes del Estado y hasta qué punto el criterio del mejor servicio a los vecinos, razonablemente argumentado en cada caso, pueden permitir procesos de fusión amparados por la legislación del Estado que se completa en el ámbito de cada Comunidad Autónoma con la legislación propia.

En la doctrina se ha discutido acerca de si las alteraciones territoriales pueden ser impuestas por el legislador general o particular. Unos (Parejo o Embid Irujo) entienden que para la garantía institucional el territorio es de libre disposición por el legislador. Otros, entre los que se encuentra Castells Arteche, entienden que cuando la población afectada se opone a la alteración entonces no procede la alteración de los términos municipales basándose en la doctrina del Tribunal Constitucional acerca de la supresión de la provincia (sentencia de 28 de julio de 1981). Es, desde luego, un tema complejo porque si afirmamos que los Entes locales son esencialmente gobiernos representativos, elegidos por los vecinos, éstos han de tener un peso fundamental en decisiones sobre alteraciones de los términos municipales. El legislador general o particular no debe ser insensible a esta realidad debiendo proceder a la fusión de municipios cuando efectivamente, de manera objetivada, se demuestre que los vecinos van a estar mejor atendidos desde la perspectiva de los servicios prestados después que con anterioridad a la fusión. 


\section{Cadernos do Programa de Pós-Graduação em Direito/UFRGS}

http://seer.ufrgs.br/ppgdir - ISSN: 1678-5029 - E-ISSN: 2317-8558

La profesora Escuín Palop esgrime tres argumentos para justificar las denominadas fusiones forzosas. Primero, la Constitución supedita a la aprobación de una ley orgánica la alteración de los términos provinciales (artículo 141) y facilita que las Comunidades Autónomas asuman competencias para alterar los términos municipales, sin someter la modificación territorial a ningún procedimiento legislativo especial, lo que lleva a pensar que el respeto que la Constitución muestra por la alteración de los términos provinciales no es mayor para los municipios que para las provincias. Segundo, la Constitución no exige ni para la modificación de los límites provinciales ni para los municipales el beneplácito de la población afectada y la sentencia del Tribunal Constitucional de 28 de julio de 1981 consideró constitucional la alteración forzosa de alguna provincia cuando se realice de acuerdo con el procedimiento establecido. Y, tercero, en el caso del municipio, la doctrina del Tribunal Constitucional permite la alteración de los términos municipales, de forma voluntaria o forzosa, siempre que se tramite por el procedimiento legalmente establecido y se resuelva por el órgano competente (2003, 1272). En cualquier caso, el concurso de la población afectada debiera ser tenido en cuenta por la autoridad autonómica que inicia de oficio el procedimiento de fusión por obvias razones. En mi opinión, no es suficiente que la institución local manifieste su voluntad en el procedimiento de alteración a favor o en contra. En el Derecho Comparado Europeo es verdad que algunos procesos de fusión municipal, como refieren Cassese para Italia o Latour para Bélgica, se han operado desde una visión complementaria de la garantía de la autonomía local con significación misma de la alteración territorial del término municipal.

Una cuestión relevante en esta cuestión se refiere a la proyección de las alteraciones territoriales de los municipios sobre la organización local y sobre la propia población municipal. El tema de la organización, del mayor o menor número de concejales, parece que depende más bien de la población que de las alteraciones de los términos municipales. Sin embargo, a poco que se estudie con cierto detenimiento se comprenderá que sin espacio físico la población no

puede asentarse y que la despoblación total de un municipio no determina por sí sola la desaparición del mismo, ya que en este caso se requiere una decisión administrativa expresa. La legislación básica no establece el número mínimo de habitantes necesario para constituir un municipio probablemente por entender que el legislador central debe respetar las diferentes formas de asentamiento de la población, que en muchos casos son características de una identidad propia forjada en el tiempo y que expresa una manera de ser y de entender la vida loca, 


\section{Cadernos do Programa de Pós-Graduação em Direito/UFRGS}

http://seer.ufrgs.br/ppgdir - ISSN: 1678-5029 - E-ISSN: 2317-8558

\section{Volume VIII | Número 2 | Ano 2013}

remitiendo esta cuestión a la legislación propia de las Comunidades Autónomas en materia local. Como es sabido, la ley de organización y atribuciones de los Ayuntamientos de 1840 y la Ley de Ayuntamientos de 1845 representan la preocupación por suprimir municipios demasiado pequeños y por condicionar los nuevos municipios a un mínimo poblacional. La ley de 1870 concretó dicha exigencia en 2.000 habitantes manteniéndose a partir de entonces dicha exigencia $(2003,1273)$

Es interesante en este punto comentar previamente la doctrina del Consejo de Estado acerca del municipio, el municipio con escasa población y escasos recursos económicos. En este sentido, el propio Consejo Estado ha puesto muchas dificultades las alteraciones municipales que den como resultado municipios de esta denominación, que es consecuencia, dice por ejemplo el dictamen de 19 de diciembre de 1991, de una reflexión histórica iniciada con la ley de 1870 vigente hasta el Estatuto de Calvo Sotelo, en el que ya se estableció una población mínima de 2.000 habitantes.

En este sentido, la sentencia del Tribunal Supremo de 9 de mayo de 1997 utiliza esta denominación y señala que en estos casos la legislación de 1985, para evitar estas situaciones de minifundismo municipal, "adopta un criterio de prevención (...) dirigiendo precisamente frente a municipios tan exiguos una orientación hacia la fusión. Y todo ello para poder cumplimentar la satisfacción del interés general, que corresponde a la población que se asienta en una determinada demarcación territorial".

El problema, como señala Escuín Palop, se encuentra en la ausencia de criterios generales que ponderen la relación óptima entre las dimensiones del término municipal y el nivel poblacional, lo que trae consigo no pocos problemas para mantener en todo el territorio un principio básico de igualdad o un mínimo común denominador en la satisfacción de las necesidades públicas locales. Aunque la cuestión quede a la legislación de las Comunidades Autónomas, el legislador general debió haber asumido algún criterio que evitara una situación de desamparo de los vecinos de tantos pueblos y villas condenados a unas pésimas condiciones de vida a causa del minifundismo municipal (2003, 1275) y hoy, de la aguda crisis económica y financiera que padecemos. 


\section{Cadernos do Programa de Pós-Graduação em Direito/UFRGS}

http://seer.ufrgs.br/ppgdir - ISSN: 1678-5029 - E-ISSN: 2317-8558

\section{Volume VIII | Número 2 | Ano 2013}

La cuestión de la participación vecinal en los procesos de alteración municipal es un asunto bien polémico. Pareciera, y así lo entiende la Carta Europea de la Autonomía Local, que en estos casos de alteraciones municipales el referéndum vecinal debiera ser determinante. Sin embargo, la legislación española no ha querido dejar estos procedimientos en manos de los vecinos. Es menester, señala el dictamen del Consejo de Estado de 8 de septiembre de 1994 la concurrencia de otros requisitos que sirvan de fundamento, entre los que la suficiencia económica ocupa, es lógico, un lugar central.

En efecto, la suficiencia económica se nos presenta como el criterio capital para proceder o no a estas operaciones. La suficiencia económica local permite a los municipios prestar los servicios y ejercer las competencias que las leyes atribuyan a los Entes locales. En los casos de minifundismo local, las fusiones precisamente se plantean para que las competencias se ejerzan en mejores condiciones y los servicios se presten con arreglo a estándares de calidad. Aunque no es el único requisito para estas operaciones de alteraciones municipales, probablemente es el más importante porque si no hay viabilidad económica para el nuevo municipio, entonces su constitución será imposible. Otras causas de la alteración municipal atienden al interés público y al orden urbanístico.

En efecto, si las condiciones de vida de los vecinos no van a mejorar, entonces la alteración poco sentido tendrá. Esta es, me parece, la principal razón de interés público que ha de justificar la alteración. Evidentemente, la mejora de las condiciones vitales está muy relacionada con la suficiencia económica, pero no son causas idénticas. Pueden citarse, si atendemos a algunos pronunciamientos del Consejo de Estado, como razones de interés público que pueden aconsejar la alteración municipal, entre otros, el establecimiento de nuevas dotaciones públicas ( dictamen de 4 de agosto de 1971), la mejora del desarrollo social ( dictamen de 5 de marzo de 1964) o la prestación de los servicios públicos indispensables ( dictamen de 25 de mayo de 1972). Es decir, se trata de mejorar la gestión pública local a través de nuevos servicios públicos o de interés general. En todo caso, la expresión mejoras de interés general hemos de vincularla a la existencia de nuevas posibilidades reales de que objetivamente mejoren las condiciones de vida de los vecinos, bien sea porque tendrán nuevos servicios públicos o porque los existentes se van a prestar en mejores condiciones. 


\section{Cadernos do Programa de Pós-Graduação em Direito/UFRGS}

http://seer.ufrgs.br/ppgdir - ISSN: 1678-5029 - E-ISSN: 2317-8558

\section{Volume VIII | Número 2 | Ano 2013}

Como señala Escuín Palop (2003, 1282), es fundamental que esas mejoras sean objetivas, permanentes y concretas. Las mejoras deben poder fundamentarse en sólidos criterios, con memorias económicas que lo demuestren y, obviamente, si estos datos se pueden suministrar y son viables, lo serán porque estaremos planteando mejoras concretas y específicas. En este punto, hay que tener en cuenta que aunque la voluntad de los vecinos no es determinante, probablemente para evitar situaciones de irracionalidad, es lo cierto que la existencia de una mayoría amplia de vecinos puede considerarse también como una razón más, bien poderosa, para proceder a la alteración municipal de que se trate.

Otro criterio ha de considerar en las alteraciones municipales es el de la confusión de los núcleos urbanos. El concepto de núcleo urbano, como señala Escuín Palop, comprende. las edificaciones, los servicios y las dotaciones públicas propias del suelo urbano tales como espacios destinados a viales, parques, jardines públicos, zonas deportivas, de recreo, de expansión o, entre otros, centros culturales o docentes. Por tanto, la confusión de núcleos urbanos no se reduce sólo a la continuidad de edificaciones, también se proyecta a la unidad del medio urbano en su conjunto $(2003,1279)$.

Los supuestos de confusión de los núcleos urbanos es más evidente en el marco del fenómeno metropolitano, dónde parece más razonable desde el punto de vista de la mejor administración de las competencias sobre el territorio que se realicen desde un solo municipio que desde varios. En estos casos, la fusión municipal o la incorporación, total o parcial puede ser, según los casos, una buena solución precisamente para evitar, como señala Escuín Palop, una acumulación de competencias para atender las mismas necesidades $(2003,1280)$.

El criterio de las ventajas económicas de la alteración municipal debe conectarse con el de suficiencia financiera. Mal se podrá justificar un expediente de fusión, por ejemplo, si se pone en peligro la suficiencia financiera local. Suficiencia financiera que debe estar garantizada para que pueda operar la causa de las ventajas económicas. En este punto, el tamaño de los municipios, por ser muy grandes o por ser muy pequeños, tiene mucho que ver con la viabilidad y rentabilidad económica. En concreto, para el caso que nos ocupa, parece fuera de toda duda que las ventajas de las fusiones municipales son evidentes si tenemos en cuenta las condiciones económicas en que se desenvuelve el minifundismo local gallego. Si los servicios se van a prestar mejor y a un menor precio, no debiera haber problemas a las fusiones. Se evitan duplicidades competenciales 
en relación con las mismas materias para una población que tiene las mismas necesidades sociales y públicas.

Así, por ejemplo, sería menester proceder a alteraciones municipales en los casos, citados por Escuín Palop (2003, 1284), de dificultades económicas que supongan la incapacidad del municipio para ejercer sus competencias en todo el término municipal (dictamen del Consejo de Estado de 25 de mayo de 1972), de imposibilidad de dos o más municipios de sobrevivir por separado (dictamen del Consejo de Estado de 27 de abril de 1961), de pérdida obvia de población, de ausencia de recursos económicos para atender los servicios obligatorios (dictamen del Consejo de Estado de 28 de noviembre de 1968) y, en, general, de insolvencia municipal acreditada por lo exiguo de los presupuestos, el reducido inventario patrimonial y el agotamiento de las fuentes de imposición permitidas por la ley (sentencia del Tribunal Supremo de 1 de abril de 1976).

Las alteraciones municipales, por tanto, tienen que venir exigidas por razones de interés público en concreto, han de traer consigo mejoras económicas que repercutan en la calidad de vecinos de los vecinos, éstos han de poder pronunciarse y la institución local resultante ha de estar en objetivas mejores condiciones de ejercer las competencias que el Ordenamiento le atribuye así como prestar mejor los servicios públicos o de interés general. Por eso, como entendió el Consejo de Estado en su dictamen de 28 de noviembre de 1968, si resulta que los Entes locales no han puesto todos los medios a su alcance para aumentar los ingresos locales y la población se opone a la alteración, es más que razonable que tal operación no proceda. Igualmente, el propio Consejo de Estado, por dictamen de 9 de abril de 1959, se mostró en contra de la alteración municipal por entender que los municipios afectados disponían de medios más que suficientes para financiar la gestión local y por constar la voluntad en contra de los vecinos. En el mismo sentido, también recoge Escuín Palop (2003, 1284) el caso de la simple disminución de los gastos de personal o administración que se derivaría de una fusión o incorporación que contara con la negativa de los vecinos pues, como señala el Consejo de Estado en dictamen de 29 de enero de 1970, existen otros medios para alcanzar dicho fin.

Hoy, en una época de crisis económica y financiera aguda, los procesos de fusión municipal serán imparables pues no se observa en el horizonte de qué otra manera van a poder garantizar su suficiencia financiera tantos pequeños municipios con el fin de ejercer las 
competencias que el legislador le atribuye y de prestar adecuadamente los servicios de su responsabilidad.

El Estado se ha reservado en estos procesos de alteración municipal, algunas competencias. Por ejemplo, en el artículo 13.1 de la ley de bases de régimen local de 1985. En efecto, el Estado debe tener conocimiento de las solicitudes de alteración municipal al tiempo de que se pida el informe al Consejo de Estado u órgano equivalente de la Comunidad Autónoma. La razón de esta información reside, como indica Escuín Palop (2003, 1289), en que con estos datos el Estado, cuando la alteración lo requiera, podrá adecuar los servicios de competencia estatal a la nueva dimensión municipal y, cuando proceda, detectar algunas irregularidades en que hayan podido incurrir las Comunidades Autónomas y así poder instar la actuación de los Tribunales de Justicia. Por lo demás, el régimen de la creación, supresión y demás alteraciones municipales es de competencia autonómica.

El número 2 del artículo 13 establece los criterios sobre los que deberán autorizarse nuevos municipios: a partir de núcleos de población territorialmente diferenciados, siempre que los municipios resultantes cuenten con recursos suficientes para el cumplimiento de las competencias municipales, y que no supongan disminución de la calidad de los servicios que se venían prestando. Entiendo que estos criterios son de general observancia por las Comunidades Autónomas a la hora de regular el régimen de las alteraciones municipales en su propio territorio.

En el párrafo tercero del artículo 13 se atribuye al Estado la competencia básica de establecer medidas, atendiendo a criterios geográficos, sociales, económicos y culturales, tendentes a la fusión de municipios con el fin de mejorar la capacidad de gestión de los asuntos públicos locales. Obviamente, esta competencia de fomento hay que entenderla en el marco de las competencias de la Comunidad Autónoma en la materia. La función de fomento debe circunscribirse a la materia económica a partir de la competencia básica del Estado de ordenación de la actividad económica general. Las medidas de fomento de las fusiones municipales desde el punto de vista geográfico habrán de fundarse en razones de interés general, al igual que la apelación a razones culturales, en este caso de más difícil justificación.

El régimen de las alteraciones de los términos municipales corresponde a las Comunidades Autónomas, en unos casos a través del propio Estatuto y en otras, la mayoría, a 


\section{Cadernos do Programa de Pós-Graduação em Direito/UFRGS}

http://seer.ufrgs.br/ppgdir - ISSN: 1678-5029 - E-ISSN: 2317-8558

\section{Volume VIII | Número 2 | Ano 2013}

través de la legislación propia en materia de régimen local. En estos casos, las Comunidades Autónomas pueden iniciar, tramitar y resolver los procedimientos de alteración precisando en el territorio propio los criterios que establece el párrafo segundo del artículo 13 de la ley de bases, en especial los de dimensión territorial y de población para las alteraciones que se produzcan.

La normativa general sobre alteración de términos municipales está en el Texto Refundido de Disposiciones Legales Vigentes en Materia de Régimen Local de 18 de abril de 1986 y en el Reglamento de Población y Demarcación Territorial de las Entidades Locales. En ambos textos normativos se prevén los casos de incorporación de uno o más municipios a otro u otros limítrofes, la fusión de dos o más municipios limítrofes, la segregación de parte del territorio de uno o varios municipios para constituir otro independiente, y la segregación de parte del territorio de un municipio para agregarlo a otro limítrofe.

En este trabajo nos interesan los dos primeros supuestos, el de incorporación y el de fusión. En caso de incorporación de uno o varios municipios a otro u otros limítrofes, según el Texto Refundido, tal alteración procederá cuando concurran notorios motivos de necesidad o conveniencia económica o administrativa, que el Tribunal Supremo en sentencia de 10 de junio de 1999 considera concepto jurídico indeterminado y, por ello, susceptible de ser aplicado por la Administración "mediante una razonada concreción de los supuestos de hecho (...) siendo mucho más exigente con el requisito de la motivación del acto administrativo, debiendo quedar clara la finalidad perseguida, que pueda potencialmente lograrse mediante los mecanismos puestos en movimiento, sin necesidad de acudir a otros menos favorables(...). La idea de conveniencia no debe ser aislada de un contexto general y referirla solo al municipio que va a experimentar el aumento de superficie, pues en ese caso lo normal es que siempre se produzca para él. La conveniencia, por eso, ha de ser para el interés común y no responder exclusivamente a un criterio de expansión, cuando las finalidades que se persiguen pueden ser satisfechas en el propio territorio del municipio que pretende la anexión". La alusión a la necesidad da idea de la gravedad en la que debe producirse la incorporación, mientras que el criterio de conveniencia económica o administrativa ha de interpretarse de acuerdo con la doctrina citada del Tribunal Supremo, que pone de manifiesto es esfuerzo de argumentación y racionalidad que es exigible a la hora de aducir dichas razones de conveniencia, nunca de arbitrariedad, que es precisamente, como gustaba decir a Locke, es la ausencia de la misma racionalidad. El Reglamento agrega a la 


\section{Cadernos do Programa de Pós-Graduação em Direito/UFRGS}

http://seer.ufrgs.br/ppgdir - ISSN: 1678-5029 - E-ISSN: 2317-8558

\section{Volume VIII | Número 2 | Ano 2013}

necesidad económica o administrativa, "cuando lo imponga la mejora de la capacidad de gestión de los asuntos públicos", un nuevo concepto jurídico indeterminado que implica un notable esfuerzo de argumentación y de concreción por parte de la Administración.

Por lo que se refiere a la fusión, la alteración que más nos interesa y la que probablemente tenga más probabilidades de éxito en Galicia, las normas estatales reclaman como condiciones para su aplicación, las siguientes: falta de recursos para atender, separadamente, los servicios mínimos exigidos por la ley, confusión de núcleos urbanos, y notorios motivos de necesidad o conveniencia económica o administrativa. En realidad la primera y segunda condición podrían ser redundantes si es que no entiende el primer requisitos, la falta de recursos, a aspectos técnicos o de personal, tal y como señala Escuín Palop (2003, 1304). Como en este supuesto de fusión se da lugar a un nuevo municipio, de acuerdo con el artículo 13.2 de la ley de bases, es menester que se realice cuando afecte a núcleos de población territorialmente diferenciados, se garantice la suficiencia económica del nuevo municipio para atender las nuevas competencias y no suponga disminución en la calidad de los servicios prestados por los municipios originarios.

Veamos a continuación, muy sucintamente, el tratamiento que de las fusiones de municipios encontramos en el Derecho Autonómico.

En Andalucía, la ley de 7 de julio de 1993 dispone que la fusión municipal podrá acordarse cuando se de alguna de estas condiciones: falta de recursos para prestar por sí o asociados los servicios mínimos impuestos por la ley, confusión entre los núcleos urbanos, y cuando existan condiciones de orden geográfico, económico, demográfico, administrativo o cualquier otra que pudiera hacerla necesaria o conveniente. La amplitud de la redacción de las causas o motivos reclama la necesidad de concretar muy bien, de argumentar a fondo las razones que aconsejen la fusión, evitando el ejercicio indiscriminado y general de las argumentaciones, pues, de lo contrario, las fusiones se producirían en atención a razones de conveniencia en ocasiones poco confesables. La incorporación de municipios podrá acordarse, dice la ley andaluza, cuando se produzca alguna de las circunstancias siguientes: insuficiencia de medios para atender los servicios obligatorios exigidos por la ley, descenso acusado y progresivo de la población, merma sustancial de su territorio por razones de obras públicas y confusión de núcleos urbanos. 


\section{Cadernos do Programa de Pós-Graduação em Direito/UFRGS}

http://seer.ufrgs.br/ppgdir - ISSN: 1678-5029 - E-ISSN: 2317-8558

\section{Volume VIII | Número 2 | Ano 2013}

En Aragón, la ley de 9 de abril de 1999 regula las alteraciones municipales. En términos generales, el legislador aragonés ha establecido tres finalidades para cualquier proceso de alteración municipal. Primera, disponer de una base territorial que mejore la capacidad económica y de gestión de los servicios públicos esenciales y obligatorios. Segunda, favorecer el autogobierno y la participación en relación con la población y sus condiciones de asentamiento sobre el territorio. Y, tercera, adaptar los términos municipales a la realidad física, social y cultural de los núcleos de población, de forma que las colectividades con conciencia de tal y con unos específicos valores históricos y tradicionales que puedan tener una representatividad. Llama la atención positivamente la importancia que el legislador aragonés otorga al autogobierno y a la participación. La incorporación o fusión de municipios procede en los siguientes supuestos: cuando como consecuencia del desarrollo urbano estemos ante municipios con núcleos de población unidos, cuando separadamente carezcan de los recursos necesarios para la prestación de los servicios mínimos obligatorios, cuando carezca de una base demográfica que posibilite el funcionamiento efectivo de una organización municipal o sea injustificable el mantenimiento, por una población reducida, del disfrute en el aprovechamiento de bienes y servicios de titularidad pública y, finalmente, cuando exista falta de presentación de candidaturas en las elecciones municipales o ausencia de funcionamiento de régimen de concejo abierto, y cuando existan otros motivos de interés general debidamente fundados. Igualmente, la creación de nuevos municipios sólo puede realizarse a partir de núcleos de población territorialmente diferenciados que cuenten con recursos suficientes para el desempeño de las competencias municipales y estén dotados de una base demográfica estable.

La ley de 7 de noviembre de 1986 del Principado de Asturias prevé entre las modalidades de alteración de los términos municipales, la fusión y la incorporación. Entre las causas generales determinantes de la alteración deben estar el consentimiento de las corporaciones afectadas y la concurrencia de uno de estos motivos: posibilidad de mejora en la prestación de los servicios públicos, especialmente los de carácter obligatorio; necesidad de unificar las dependencias administrativas de núcleos urbanos pertenecientes distintos concejos en los que se haya producido o se vaya a producir su confusión como consecuencia de su expansión urbanística; insuficiencia de medios económicos, materiales o personales, para atender separadamente la prestación de los servicios obligatorios exigidos por la ley, y, notorios motivos de necesidad o conveniencia económica o administrativa que así lo aconsejen atendidas las 


\section{Cadernos do Programa de Pós-Graduação em Direito/UFRGS}

http://seer.ufrgs.br/ppgdir - ISSN: 1678-5029 - E-ISSN: 2317-8558

\section{Volume VIII | Número 2 | Ano 2013}

circunstancias de orden geográfico, demográfico, social o cultural que concurran. Además, el legislador asturiano prevé cuatro razones en cuya virtud puede prescindirse del consentimiento vecinal: cuando la necesidad de unificar las dependencias administrativas se presente como perentoria, cuando la insuficiencia de recursos para tender los servicios obligatorios tenga una notoriedad acusada, imposibilidad de mantener una organización administrativa independiente por la despoblación del concejo, y cuando la mayoría de los residentes vecinos en una zona territorialmente delimitada inste directamente al órgano autonómico competente para incorporarse a otro término municipal. La lista de conceptos jurídicos indeterminados que jalonan el régimen de las alteraciones de términos, obliga a los Gobiernos y Administraciones autonómicas a trabajar en orden a perfilar, materializar, puntualizar y concretar, lo que exige memoria justificativas bien argumentadas a partir de datos y elementos objetivos.

En Castilla-La mancha, la ley de 14 de marzo de 1991 regula las alteraciones de términos municipales. En estos casos, la fusión o incorporación procede cuando existe confusión de los núcleos de población que sean capitalidad de los respectivos municipios, cuando hay falta de los recursos económicos necesarios para preservar los servicios mínimos previstos en la legislación del Estado, cuando hay ausencia de población u organización municipal (cuando no existan listas electorales que concurran al proceso electoral local o cuando dimitieran los miembros electos y no fuera posible la designación de una comisión gestora), cuando concurran motivos de interés general apreciados por la Administración autonómica o cuando medie solicitud de las dos terceras partes de los vecinos del municipio a incorporar, siempre que acrediten los motivos que aleguen para la alteración. De nuevo, pues, nos topamos con fórmulas muy generales que habrán de ser gravemente motivadas para evitar que la arbitrariedad campee en toda esta materia.

En la ley de Castilla y León de 4 de junio de 1998 se establecen las causas de la creación de un municipio por fusión: cuando separadamente carezcan de capacidad o recursos suficientes para atender los servicios mínimos exigidos por la ley, cuando sus núcleos de población se confundan como consecuencia del desarrollo urbanístico, y cuando existan notorios motivos demográficos, económicos, administrativos o de cualquier otro carácter que pudieran hacerla necesaria o conveniente.

En Cataluña hay que estar a la ley de 19 de noviembre de 1998 que modificó el Reglamento de sobre Demarcación Territorial y Población de 24 de mayo de 1988, en la que se 
establecen los presupuestos o condiciones generales que han de presidir estas alteraciones de los términos municipales. En este sentido, estas operaciones territoriales deben fomentar la conciencia de colectividad y el deseo de representación de los intereses propios, así como la capacidad para gestionar los servicios públicos que el municipio tiene encomendado, la existencia de valores históricos y tradicionales y al suficiencia económica. En este marco, la fusión se produce cuando exista dificultad para gestionar los servicios obligatorios por la insuficiencia de medios económicos, materiales y personales, cuando los núcleos de población formen un continuo urbano (cuando resulte que entre los suelos clasificados de urbanos y urbanizables no hay solución de continuidad) o cuando consideraciones de orden geográfico, demográfico, económico o administrativo lo hacen necesario o aconsejable. La ley de 1998 encomienda al gobierno autonómico que impulse medidas de fomento para la fusión o agregación voluntaria de municipios cuando consideraciones de orden geográfico, demográfico, económico o administrativo lo aconsejen.

Por Decreto Legislativo de 28 de abril de 2003 se aprobó en Cataluña el Texto Refundido de la Ley municipal y de régimen local de Cataluña, en la que encontramos algunos preceptos relevantes. Por ejemplo, el artículo 20 en materia de fomento de fusiones, y el 21 relativo al fomento de mancomunidades. En materia de fusiones, el legislador dispone que el Gobierno adoptará medidas de fomento a las fusiones o agregaciones voluntarias de municipios cuando consideraciones de orden geográfico, demográfico, económico o administrativo así lo aconsejen. Las medidas de fomento pueden consistir, entre otras, en ayudas económicas y técnicas para estas iniciativas, previsiones especiales en los criterios de distribución del Fondo de cooperación local de Cataluña, criterios prioritarios o especiales en la asignación de subvenciones finalistas, o previsiones especiales para la realización de inversiones a cargo de la Administración de la Generalidad.

Por lo que se refiere al fomento de las mancomunidades, el artículo 21 del Texto Refundido dispone que el Gobierno impulsará la constitución de mancomunidades cuando la mejor garantía en la prestación de servicios públicos de competencia municipal y la eficacia necesaria en la prestación lo hagan conveniente. En concreto, estas medidas pueden consistir en ayudas económicas y técnicas para estas iniciativas, previsiones especiales en los criterios de distribución del Fondo de cooperación local de Cataluña y en la asignación de subvenciones 


\section{Cadernos do Programa de Pós-Graduação em Direito/UFRGS}

http://seer.ufrgs.br/ppgdir - ISSN: 1678-5029 - E-ISSN: 2317-8558

\section{Volume VIII | Número 2 | Ano 2013}

finalistas, y cualquier otra que conduzca a la mejor garantía en la prestación de los servicios públicos municipales y a la eficacia necesaria en su prestación.

Si aún así, si las medidas de fomento para impulsar fusiones y mancomunidades no fueran suficientes para garantizar un nivel homogéneo en la prestación de los servicios públicos municipales, entonces el Gobierno puede iniciar un proceso de reforma de la organización municipal en los ámbitos territoriales de Cataluña que así lo requieran

Por lo que se refiere a Galicia, la ley de Administración local de 22 de julio de 1997 regula esta materia. En concreto, la Comisión Gallega de Delimitación Territorial es el órgano de estudio, informe y propuesta en relación con las cuestiones concernientes a la determinación, revisión y modificación de los límites territoriales de los Entes locales de nuestra Comunidad Autónoma. Por lo que hace a la fusión municipal, es necesario, según la ley, que concurra alguno de los cuatro requisitos siguientes. Primero: que se confundan los núcleos de población que sean capitalidad de los respectivos municipios. Segundo, que separadamente carezcan los municipios de los medios necesarios para mantener los servicios mínimos. Tercero, que aparezcan notorios motivos de necesidad o conveniencia económica, administrativa o consideraciones de orden geográfico o demográfico. Cuarto, que del proceso de fusión se deriven significativas ventajas para ambos municipios y así sea apreciado por ellos. La ley diseña también el procedimiento de alteración de los términos municipales, en el que debe intervenir el Consello Consultivo. El procedimiento puede iniciarse de oficio por la consellería competente o a instancia de cualquiera de los municipios interesados o de la diputación provincial.

En la ley de 22 de septiembre de 1993 de La Rioja se establecen los objetivos que habrán de perseguir las alteraciones territoriales. A saber: mejorar los servicios de competencia municipal e incrementar la capacidad de gestión de las Entidades locales afectadas. En relación con la fusión municipal, la ley autonómica citada determina los motivos que pueden dar lugar a un nuevo municipio por fusión: confusión de las capitalidades de ambos municipios, insuficiencia de los recursos para prestar los servicios mínimos exigidos por la ley, ausencia de población o de organización municipal y, finalmente, cuando lo soliciten las dos terceras partes de los vecinos de los municipios afectados. 


\section{Cadernos do Programa de Pós-Graduação em Direito/UFRGS}

http://seer.ufrgs.br/ppgdir - ISSN: 1678-5029 - E-ISSN: 2317-8558

\section{Volume VIII | Número 2 | Ano 2013}

En Madrid, la Ley de 11 de marzo de 2003, de Administración local, señala que las alteraciones de los términos municipales se orientarán al establecimiento de una adecuada dimensión territorial de los municipios o a mejorar su capacidad económica y de gestión de los asuntos públicos locales. En relación con las fusiones e incorporaciones, la ley dispone que estas operaciones podrán llevarse a cabo siempre que concurra alguna de las siguientes circunstancias. Primera, que los municipios afectados carezcan de recursos suficientes para prestar los servicios mínimos impuestos por la legislación básica estatal. Segunda, cuando se confundan sus núcleos de población. Tercera, cuando desparezcan o disminuya notablemente alguno de los elementos constitutivos del municipio. Cuarta, cuando sea preciso para mejorar la capacidad de gestión de los asuntos públicos locales, existan necesidades o conveniencia económica o administrativa o razones geográficas o demográficas.

Finalmente, en Navarra, la competencia de alteración municipal es de la Comunidad Autónoma tal y como lo previene el artículo 46 del Estatuto, de la LORAFNA. Ahora, con la Ley foral de 2 de julio de 1990, se regula en concreto el régimen de las alteraciones de términos municipales que han de perseguir, según esta ley, mejorar la prestación de los servicios de competencia municipal, incrementar la capacidad de gestión de los Entes locales afectados, adaptar los términos municipales a las realidades físicas, demográficas, urbanísticas y culturales, y facilitar la participación ciudadana en los asuntos locales. En materia de fusión e incorporación, el legislador navarro entiende que pueden practicarse en los siguientes supuestos: cuando carezcan separadamente de medios económicos suficientes para atender a los servicios mínimos exigidos en la ley, cuando se confundan sus núcleos urbanos como consecuencia del desarrollo urbanístico y cuando concurran motivos notorios de necesidad o conveniencia económica o administrativa.

En fin, la concreción y precisión que hacen las Comunidades Autónomas del artículo 13 de la ley de bases en orden a las fusiones e incorporaciones municipales subrayan la viabilidad económico-financiera, la garantía de la suficiencia financiera, la existencia de confusión de núcleos de población, la inexistencia de organización o población, la mejora de la prestación de los servicios obligatorios, la mejora de la capacidad de gestión pública local, fomentar la participación ciudadana en los asuntos locales o adaptar los términos municipales a las realidades físicas, demográficas, tradicionales, urbanísticas y culturales. 


\section{EXPERIENCIAS DE FUSIONES MUNICIPALES}

Las distintas fusiones municipales acontecidas en el pasado, como ya hemos indicado, fueron ocasionadas en su gran mayoría por la incapacidad de los municipios de prestar los servicios de su competencia debido a las dificultades financieras existentes. Hoy, en una situación de aguda crisis económica y financiera, la posibilidad de las fusiones constituye una realidad que debe plantearse si es que se pretende que los Entes locales sean un instrumento adecuado para la mejora de las condiciones de vida de los vecinos y la mejor gestión y administración de los asuntos locales.

Como es sabido, en la segunda mitad del siglo pasado se inició un proceso de fusiones municipales que redujo drásticamente el número de Entes locales, más a instancia del poder político de turno que a la propia voluntad de los vecinos. Se demuestra una vez más que a pesar de que la población es elemento capital de la institución municipal no siempre, por obvias razones, está en condiciones de iniciar procesos que pueden afectar a sentimientos, emociones y otras consideraciones subjetivas relativas al sentido de las instituciones y a su historia. En realidad, la conformación en esos años del Estado de bienestar trajo consigo la necesidad de articular nuevos servicios públicos que, con gracoste económico, impusieron una nueva adaptación de la realidad local a las nuevas exigencias públicas y sociales. Según el Consejo de Europa, entre 1950 y 1992, la mayor parte de los países redujeron notablemente el número de municipios. Bulgaria el 88\%, pasando de 2.178 a 255; Suecia el 87\%, pasando de 2.281 a 286; Dinamarca el 80\%, pasando de 1.387 a 285; Bélgica el 78\%, pasando de 2.669 a 589; Reino Unido el 76\%, pasando de 2.028 a 484; Alemania el 67\%, pasando de 24.272 a 8.077; Chequia el 44\%, pasando de 11.051 a 6.196; Austria el 42\%, pasando de 3.999 a 2.301; Noruega el 41\%, pasando de 744 a 439; y Holanda, el 36\%, pasando de 1.015 a 647.

Sin embargo, en España y Francia, dónde el inframunicipalismo es más fuerte, la reducción de municipios apenas alcanzó un 12\% y un 5\% respectivamente para el período de 1950 a 1992. En Italia y Portugal, por el contrario, en lugar de reducir municipios, los aumentaron: en Italia se pasó de 7.781 a 8.100 y en Portugal, de 303 a 305 municipios. 


\section{Cadernos do Programa de Pós-Graduação em Direito/UFRGS}

http://seer.ufrgs.br/ppgdir - ISSN: 1678-5029 - E-ISSN: 2317-8558

\section{Volume VIII | Número 2 | Ano 2013}

En Alemania, de las más de 24.000 comunas que tenían en 1960, el $70 \%$ con una población inferior a los 1.000 habitantes, pasaron a ser, tras la reunificación, 8.400, con un tamaño siete veces mayor. En Bélgica, la tendencia a la reorganización local se produce con mayor intensidad en la década de los 70 del siglo pasado cuando sus Entes locales se redujeron en una cuarta parte. El caso del Reino Unido también es significativo pues la reducción operada es notable. La metodología empleada en Gran Bretaña es bien ilustrativa de la importancia de que estos procesos de reorganización local se aborden a partir de estudios serios y minuciosos con presencia de todos los sectores implicados: sociólogos, economistas, juristas, geógrafos... y, sobre todo, teniendo presente la naturaleza de los servicios y prestaciones que habrían de realizar los Entes locales. Como es sabido, tras diez años de trabajos, la Local Government Act de 26 de octubre de 1972 aprobó el nuevo mapa local británico. Dinamarca es ciertamente uno de los países que ha efectuado más fusiones municipales reduciendo a una quinta parte su número de Entes locales. La integración de Entes locales se produjo también en Suiza, pasando de 3.203 municipios en 1.850 a los 2.880 actuales. Sin embargo, en el área mediterránea, las fusiones no han tenido mucho éxito. El caso de España y Francia así lo atestigua. Y dentro de España, en Galicia hemos pasado de 303 municipios a 305 en la última década.

Desde luego, si se pretende implementar una política de fusiones municipales es menester premiar a quienes asuman esta operación de alteración de los términos municipales. Así, por ejemplo, la ley de promoción para la fusión de municipios distritales de Perú, de 20 de mayo de 2007, dispone toda una serie de incentivos para las fusiones: desde subvenciones de un fondo público hasta la asesoría directa de la presidencia de la República para la formación del personal y para la preparación del plan de desarrollo concertado pasando por la prioridad para la asignación de recursos de cooperación técnica por el consejo de ministros y para el financiamiento de adquisición de maquinaria y equipos a través del programa de equipamiento básico municipal. Si no existen estímulos a la fusión con los que transmitir a la población que es rentable unirse, tales alteraciones de los términos municipales son imposibles, especialmente por razones políticas fáciles de colegir, que no de justificar.

En Taiwan, la consideración de municipio especial ofrece mayor autonomía en materia tributaria y en lo que se refiere a la propia Administración pública. Por eso algunas ciudades y 
distritos han solicitado ante el ministerio del interior la pertinente fusión con el fin de convertirse en locomotoras del desarrollo local.

En Asturias, por ejemplo, el catedrático de economía de la Universidad de Oviedo Carlos Monasterio es partidario de las fusiones municipales en su región porque el mapa local actual es deudor de situaciones económicas y demográficas de hace doscientos años, mientras que hoy en día hay concejos con muy poca población, sin apenas actividad económica. Es más, con la actual división territorial y su reducida capacidad de gestión no se puede ofrecer una red de servicios potente. Además, la población es un elemento muy importante para la captación de fondos, sobre todo europeos. Según este profesor, la fusión de municipios beneficiará a los ciudadanos porque dispondrán de mejores servicios, aunque reconoce que el tema de las alteraciones de los términos municipales es un tema espinoso por que donde hay tres o cuatro alcaldes pasaría a haber uno. Desde luego, sin un mínimo consenso vecinal estas operaciones están llamadas al fracaso pues el $70 \%$ de los concejales españoles lo son de pueblos de menos de 5.000 habitantes. Por su parte, el catedrático de geografía de la misma Universidad, tras reconocer que el mapa municipal asturiano le parece inamovible desde el punto de vista político, reconoce que desde una óptica económica muchos concejos deberían de fusionarse para mejorar las prestaciones a los vecinos ya que las prestaciones de los pequeños municipios son muy limitadas.

En 1990, el Comité de las Regiones, tal y como recuerda el informe del Círculo de Empresarios de Galicia en su página 18, señalaba en un dictamen al referirse a España que es responsabilidad primaria de las Comunidades Autónomas la política de fomentar fusiones o agrupaciones de municipios, aunque hasta el momento lo que se aprecia es un estímulo tímido a la constitución de mancomunidades voluntarias para la prestación de determinados servicios. En realidad, si las mancomunidades voluntarias funcionan, es más probable que una política de fusiones municipales pueda producirse sin graves problemas puesto que puede decirse que la consecuencia lógica de una inteligente política de asociacionismo voluntario de municipios es su fusión.

Una pregunta que debemos formularnos a la luz de la experiencia comparada es la relativa a si es recomendable o no establecer un número mínimo de habitantes por municipio de manera que se asegure la viabilidad económica. Por ejemplo, el propio Consejo de Europa propuso algunas ratios para algunos países: de 5.000 a 6.000 en Dinamarca, 5.000 en Noruega, de 6.000 a 
7.000 en Países Bajos, 8.000 en Suecia. En ningún caso se contemplan municipios de menos de 5.000 en habitantes. En España, de 8.112 municipios, el 84 \% (6.082) tienen menos de 5.000 habitantes con una población que apenas llega al 15\% del total nacional. En Galicia, estos municipios de menos de 5.000 habitantes, que son 199 de 305, suponen el $63.2 \%$ del total de municipios y el $17 \%$ de la población de Galicia.

\section{LA CUESTIÓN COMPETENCIAL: EL TEMA PENDIENTE.}

La cuestión competencial en España es uno de los temas más importantes para el desarrollo territorial. Mientras sigamos en un cierto entorno de ambigüedad y abstracción en cuya virtud se producen solapamientos y duplicidades entre diversas Administraciones territoriales, será difícil avanzar en esta materia. Por eso, no sería descabellado iniciar un estudio multidisciplinar acerca de cuáles deberían ser las competencias propias de las diferentes Administraciones territoriales con el fin, más adelante, de proceder a las reformas normativas que fuera menester. En concreto, la situación de las competencias en materia local es especialmente grave y mientras no se soluciones las cuestiones que atienden a las alteraciones de los términos municipales estarán siempre en el candelero pero sin poderse aplicar.

Como es sabido, nuestro ordenamiento jurídico contiene principios aplicables al régimen jurídico de los Entes locales que contienen rasgos comunes con el principio de subsidariedad. Así, en el artículo 137 de la Constitución, aparece la idea de un Estado descentralizado, que reserva a cada instancia territorial un ámbito judicial delimitado por el respectivo interés público propio. El artículo 140 de la Carta magna incide en la misma idea asignando el Gobierno y la Administración municipal a los Ayuntamientos. En el artículo 2 de la ley de bases encontramos la doctrina de la necesaria organización de los poderes públicos a partir del principio de proximidad al ciudadano, cuando dispone que se deberá atribuir competencias a los Entes locales "en atención a las características de la actividad pública de que se trate y a la capacidad de gestión del Ente local, de conformidad con los principios de descentralización y de máxima proximidad de la gestión administrativa a los ciudadanos". Por su parte, el artículo 28 de la citada ley de bases, donde se regulan las actividades complementarias de los municipios, concibe determinadas materias como áreas en donde siempre cabe un desarrollo más detallado en el ámbito local. 


\section{Cadernos do Programa de Pós-Graduação em Direito/UFRGS}

http://seer.ufrgs.br/ppgdir - ISSN: 1678-5029 - E-ISSN: 2317-8558

\section{Volume VIII | Número 2 | Ano 2013}

Otro caso de aplicación clara de la subsidiariedad como reserva de un espacio competencial a la instancia inferior, pese a la aparición de Entes superiores, lo encontramos en el artículo 43.4 de la ley de bases cuando impide que la creación de comarcas pueda suponer la pérdida de las competencias municipales para prestar los servicios esenciales señalados en el artículo 26 o la privación de toda intervención en cada una de las materias enumeradas en el art. 25.2, también de la ley de bases.

Asimismo es de gran interés, al tratar del principio de subsidariedad y su relación con las Entidades Locales, hacer referencia a la Carta Europea de la Autonomía Local. En efecto, elaborada en el marco del Consejo de Europa, y ratificada por nuestro país el 20 de enero de 1988, su trascendencia es innegable puesto que se trata de un texto normativo incorporado a nuestro Derecho interno y por tanto, plenamente invocable ante los Tribunales de Justicia españoles. Esta invocabilidad es, precisamente, una de las características que le otorga mayor actualidad y justifica que le dediquemos nuestra atención.

Entre los principios que la Carta Europea de la Autonomía Local consagra, destacan la suficiencia de recursos, la autonomía para el gasto y el ingreso, el derecho a ser oído cuando se dicten medidas y criterios de redistribución de los recursos, la preferencia de subvenciones y el libre acceso al mercado para concretar operaciones de crédito destinadas a gastos de inversión. Criterios todos ellos que deberían aconsejar la realización de un estudio integral acerca de las competencias de los Entes públicos en España de acuerdo con los respectivos intereses públicos territoriales.

La Carta nos plantea que las Entidades Locales ordenan y gestionan los asuntos públicos en beneficio de sus habitantes y, que sus órganos de gobierno son directamente representativos de dichos ciudadanos. Ello viene a suponer, en definitiva, la asunción de competencias propias sobre la parte importante de los asuntos públicos y la financiación suficiente para ejercitarlas. En la carta se parte directamente de dos principios: uno, que ya ha sido mencionado anteriormente, el de subsidariedad y otro, el de proximidad, la cercanía a los ciudadanos como criterio de atribución competencial. Así se expresa en el punto primero del apartado tercero del artículo cuarto de la Carta, al establecer que: 
"el ejercicio de las responsabilidades públicas debe, de modo general, incumbir preferentemente a las autoridades más cercanas a los ciudadanos".

Al mismo tiempo, el mismo apartado tercero en su punto segundo exige que:

"La atribución de una responsabilidad a otra autoridad debe tener en cuenta la amplitud o la naturaleza de la tarea o las necesidades de eficacia o economía".

En relación con este punto hemos de agregar otros tres elementos normativos. De una parte, la potestad reglamentaria se realiza según el artículo 3 de la Carta "en el marco de la Ley". De otra, la libertad de los Entes Locales para ejercer su iniciativa en toda materia que no esté excluida de su competencia o atribuida a otra autoridad. Finalmente, se establece una reserva reglamentaria en materia de organización local.

La Carta afirma el principio de autogobierno, al establecer el ya citado artículo 3 que la gestión de los asuntos públicos la realizará el Ente local bajo su propia responsabilidad. Este principio de autogobierno es, sin duda, un instrumento interpretativo fundamental con relación al régimen de las competencias de los Entes locales.

Hay otro aspecto de la Carta Europea que no podemos dejar de mencionar por la conexión que se está produciendo últimamente entre el principio de subsidiariedad y el problema del déficit democrático de las Instituciones de la Unión Europea. Me refiero a la conexión de la autonomía local con el principio democrático. En efecto, el Preámbulo de la carta señala a los entes locales como un ámbito privilegiado de la participación de los ciudadanos en la gestión de los asuntos públicos como cuna de la democracia: "La defensa y el fortalecimiento de la autonomía local en los diferentes países de Europa representan una contribución esencial en la construcción de una Europa basada en los principios de democracia y descentralización". Por eso, en orden a las decisiones que se puedan adoptar en materia de alteraciones territoriales, especialmente en el caso de las fusiones, es menester valorar el grado de adhesión de los vecinos a estas políticas puesto que la iniciativa administrativa, si se dicta al margen de la voluntad del pueblo, estaría llamada al fracaso. 


\section{Cadernos do Programa de Pós-Graduação em Direito/UFRGS}

http://seer.ufrgs.br/ppgdir - ISSN: 1678-5029 - E-ISSN: 2317-8558

\section{Volume VIII | Número 2 | Ano 2013}

Esta reflexión parte esencialmente del principio democrático, desde la perspectiva de posibilitar que los ciudadanos se sientan representados con la máxima intensidad posible en las decisiones que les afectan. De aquí la preferencia por la autoridad representativa más próxima, que sólo debe quedar desplazada cuando los efectos benéficos de una autoridad superior compense la pérdida de integración democrática. En este sentido, la propia Carta recoge, como no podía ser de otra forma, el principio de subsidariedad al contemplar la proximidad a los ciudadanos como criterio de atribución competencial, estableciendo que el ejercicio de las competencias públicas debe de modo general incumbir preferentemente a las autoridades más cercanas a los ciudadanos. Se trata, así, de acercar la Administración al ciudadano. Algo que aquí, en España, se ha dado en llamar la Administración común, ordinaria, general, sincronizada o única.

La Administración común exige necesariamente que sean los Entes Locales los que presten un mayor número de servicios y dispongan de una correlativa carga administrativa. La doctrina de la Administración común supone, pues, un claro reforzamiento del Ente titular de competencias en su propia demarcación territorial, lo cual debe propiciar un mayor protagonismo de Ayuntamientos, Cabildos, Consejos y Diputaciones en el ejercicio de las competencias sobre su propio territorio.

La Administración común no es incompatible con la función que la Constitución asigna a las Corporaciones Locales. Muy al contrario, ya que el proceso de redistribución de competencias no se completaría si no se produjese un proceso paralelo de desconcentración de competencias de la Administración Autonómica hacia las Administraciones Locales, en todos aquellos servicios en que su prestación por estos entes redundara en un mejor servicio al ciudadano, que es en definitiva la pieza clave del sistema en función del cual debe reorientarse todo el aparato administrativo.

Siendo ello así, al haberse producido en España un proceso de distribución territorial del poder con el desarrollo del fenómeno autonómico, resulta necesario que se reconozca, en esta estructuración del reparto del poder político establecido por la Constitución, un lógico protagonismo de las Entidades Locales. Sin embargo, durante mucho tiempo se ha prestado una atención más que prioritaria a la descentralización de competencias del Estado hacia las Comunidades Autónomas, con un cierto olvido de las Entidades Locales. 


\section{Cadernos do Programa de Pós-Graduação em Direito/UFRGS}

http://seer.ufrgs.br/ppgdir - ISSN: 1678-5029 - E-ISSN: 2317-8558

\section{Volume VIII | Número 2 | Ano 2013}

Es cierto, como es bien sabido, que la Constitución no ha establecido un listado de materias sobre las que los Entes Locales ejerzan sus competencias. Pero también es posible -y deseable- que se ponga en marcha, una vez que el contenido propio de las autonomías este bien definido, una auténtica descentralización hacia los Entes Locales, habida cuenta que es habitualmente el legislador sectorial autonómico quien tiene la última palabra sobre la funcionalidad competencial de los Entes Locales.

La realidad competencial de los Entes locales es criticable por la existencia de un cierto descontrol en la realización de actuaciones, atendiéndose a auténticas "modas". Así a comienzos de los años 90 del siglo pasado, fue frecuente la eclosión de patronatos y empresas municipales, mediante la utilización de distintas tipologías societarias, ordinariamente sin estudios serios económicos, de gestión y financieros que los sustentasen, para poder desarrollar, en un marco de huida del Derecho Administrativo, las actividades que se pretendían, lo que ha provocado que gran número de ellas sean prácticamente inoperativas.

También podemos recordar la tendencia de las Corporaciones Locales de asumir cada vez mayor nivel competencial en aras a la actividad positiva de generación de empleo, fomento de la economía, y desarrollo socio-económico de la población, lo que supone un salto cualitativo respecto a una visión tradicional y arcaica de los entes locales como embalses estancados de competencias no productivas. Sin duda, el desarrollo competencial de los Entes locales debe pasar por el fenómeno del asociacionismo, otorgando un papel importante a las áreas metropolitanas y las mancomunidades de municipios como vías en transición a fenómenos de fusión o incorporación de municipios, sin olvidarnos del papel de la provincia como instancia garantizadora de los servicios en los pequeños municipios y como posible opción organizativa para la ejecución de determinadas políticas propias de base autonómica en su territorio.

En este sentido, conviene recordar que desde el propio Parlamento se ha instado a la redefinición del marco competencial a partir del principio de subsidariedad. Desde esta perspectiva, el significado del denominado pacto local es, pues, la respuesta a la insuficiencia de los instrumentos jurídicos para definir positivamente y hacer eficaz el contenido competencial concreto que la autonomía local reclama para la gestión de los intereses propios. 


\section{Cadernos do Programa de Pós-Graduação em Direito/UFRGS}

http://seer.ufrgs.br/ppgdir - ISSN: 1678-5029 - E-ISSN: 2317-8558

\section{Volume VIII | Número 2 | Ano 2013}

A este respecto, la situación actual de las competencias de los Entes Locales ha motivado que por diversos sectores se haya apuntado una progresiva pérdida del papel que deben desempeñar las Corporaciones Locales en el conjunto del Estado autonómico, con la consiguiente disminución de su poder de iniciativa y de respuesta, cuya causa puede encontrarse en una cierta cultura política imperante en las instituciones territoriales superiores, Comunidades Autónomas y Administración del Estado, que no se han conducido con el dinamismo necesario para dar satisfacción al autogobierno de los intereses locales.

Respecto a la posición de los poderes locales, uno de los mayores problemas es la complejidad administrativa y otro la estructura competencial. El proceso de descentralización observado a nivel internacional -con la posible excepción actual del Reino Unido- ha supuesto la aparición o el reconocimiento de Gobiernos y Administraciones regionales. Este proceso positivo de descentralización y, por tanto de acercamiento de los poderes públicos al territorio y al ciudadano, supone problemas de competencias y funciones. El desarrollo regional pone en marcha a menudo mecanismos de centralización interna, con asunción de competencias locales y reducción, por tanto, del espacio del gobierno local. Pero la situación también es aquí diferente, por cuanto en algunos países las regiones o niveles de administración similares son considerados parte de la administración local (Francia, Reino Unido).

Los procesos de descentralización observados en la mayoría de los países, que convierten esta descentralización en una característica de nuestro tiempo, conllevan también problemas comunes de solapamiento de competencias, de duplicación a veces de los servicios y, lo que es más importante, de lagunas en la resolución de ciertos problemas.

La complejidad de las sociedades actuales hace lógica una relativa complejidad y una pluralidad de Administraciones públicas que operan en el territorio. Lo importante es saber convertir esta complejidad en un sistema eficaz de resolución de los problemas de los ciudadanos. Un reto del futuro inmediato será el de tratar mecanismos de cooperación que, mediante técnicas de negociación y contrato, permita una mayor eficacia y eficiencia pública, a la vez que garanticen el principio de responsabilidad. La complejidad no ha de impedir identificar claramente las administraciones responsables en cada caso, garantizando la seguridad jurídica y la transparencia frente a los ciudadanos. 


\section{Cadernos do Programa de Pós-Graduação em Direito/UFRGS}

http://seer.ufrgs.br/ppgdir - ISSN: 1678-5029 - E-ISSN: 2317-8558

\section{Volume VIII | Número 2 | Ano 2013}

La actuación de los poderes locales es incuestionable en su ámbito territorial, pero en dicha área intervienen también otras administraciones, bien directamente o bien de forma indirecta a través de decisiones normativas que afectan a los municipios. En el primer caso, la intervención directa, parece obvio reclamar la mejora de los mecanismos de coordinación operativa, que son todavía muy deficitarios. La Administración del Estado y las Administraciones regionales intervienen a menudo sobre el territorio sin la necesaria implicación del municipio.

En el ámbito del Consejo de Europa, como ya se ha destacado, la Carta Europea de la Autonomía Local consagra el concepto de autonomía local, afirma el principio democrático que rige sus destinos, y reconoce la aplicación de la subsidariedad o proximidad así como la autonomía y suficiencia financiera así como la protección legal de su autonomía.

Refiriéndonos al caso español, se ha planteado en los últimos años una revisión general de las competencias de las Entidades locales, incardinado en este proceso de fortalecimiento de poder local que encuentra su base en la Carta Europea de la Autonomía Local. Pues bien, dicho proceso, como ya he señalado, podría girar en torno a los siguientes principios.

Primero, la Administración del Estado y las Comunidades Autónomas únicamente deberán asumir aquellas competencias que no sea posible residenciar en la Administración Local. Segundo, debe permitirse a los Entes Locales la elaboración de políticas propias mediante el reconocimiento de potestad normativa. En este sentido debiera implantarse una interpretación flexible del principio constitucional de reserva de Ley aplicado a la Administración Local. Tercero, la atribución de competencias no debe limitarse a funciones meramente ejecutivas. Además, debe potenciarse la descentralización de funciones en perjuicio de la delegación y, en cualquier caso, deberán evitarse las restricciones que minoren la efectividad de la autonomía local. Cuarto, en aquellas Comunidades Autónomas donde no existan deberán constituirse Comisiones Autonómicas de Régimen Local, como mecanismo que permita a las Entidades Locales participar en los procesos de planificación y ordenación de los asuntos que les afecten.

Esta potenciación de los Entes locales va ligada a la idea de subsidariedad, ya que la mayor proximidad de los municipios a los intereses ciudadanos tendría que proyectarse en una descentralización de funciones y competencias en favor de las Entidades Locales, extrayendo en 
su plenitud las posibilidades de delegación de competencias estatales o autonómicas en su favor y abordando, si ello fuera preciso, las reformas legales necesarias para alcanzar ese objetivo.

Para alcanzar estos fines se planteó la necesidad de suscribir un Pacto, de carácter político y territorial, que permitiese abordar de un modo lógico, claro y de forma conjunta el futuro, las competencias y la posición de las Entidades Locales y que debería basarse en una serie de principios, entre los que pueden citarse: la autonomía en la gestión de los intereses propios, la subsidariedad, la descentralización y el acercamiento de la gestión, la eficacia en el desempeño de la función, la eliminación de duplicidades y la cooperación y coordinación ejecutivas.

Bajo la rúbrica del Pacto Local se encuentra, realmente, un complejo proceso de redistribución territorial del poder, que afecta al conjunto de los Gobiernos públicos y de las Administraciones territoriales, complementario de la construcción del denominado Estado autonómico. Un proceso de redistribución territorial que se guía por el principio de subsidariedad o, si se prefiere denominarlo así -dado el grafismo del término- por el de proximidad, entendiendo como la atribución preferente de las responsabilidades públicas a las autoridades más cercanas a los ciudadanos, debiendo atenderse solamente a la amplitud o a la naturaleza de la tarea, así como a las necesidades de eficacia o economía, para apartarse de tal criterio atribuyendolas a una autoridad de nivel territorial superior, como certeramente destaca la Carta Europea de la Autonomía Local.

Obviamente, el gran beneficiario de este segundo proceso descentralizador en la historia de la democracia española surgida de la transición política y de la Constitución de 1978 debe ser el poder local, que hasta ahora se había limitado a contemplar el surgimiento y la consolidación de ese novedoso y decisivo nivel de poder territorial constituido por las Comunidades Autónomas (que él mismo había contribuido a crear de forma también decisiva mediante el ejercicio de la iniciativa que a las Entidades locales confiere el título VIII de la Constitución), sin beneficiarse de forma significativa del proceso descentralizador que el Estado autonómico ha comportado. El objetivo es dotar a las corporaciones locales del marco legal de los medios y las competencias que les permitan ejercer un papel que es fundamental al servicio de la sociedad en su conjunto. Para ello, las Entidades locales han de tener un papel clave el modelo de desarrollo territorial y han de ser capaces de explotar las potencialidades de las reformas legislativas recientemente aprobadas por el Parlamento. 


\section{Cadernos do Programa de Pós-Graduação em Direito/UFRGS}

http://seer.ufrgs.br/ppgdir - ISSN: 1678-5029 - E-ISSN: 2317-8558

\section{Volume VIII | Número 2 | Ano 2013}

Esta reforma encuentra su justificación en la previsión de un proceso de descentralización de funciones desde el Estado y, en su caso, desde las Comunidades Autónomas hacia las Entidades Locales obliga a mejorar previamente la capacidad de respuesta y efectividad de las instituciones locales, para asegurar el correcto desempeño de las nuevas competencias que se le confían.

En el ámbito autonómico, debe destacarse no sólo la necesidad de una mayor transferencia de competencias y de recursos financieros a las Entidades locales, sino también la del cumplimiento del principio del carácter predominantemente no finalista de las transferencias y subvenciones de otras Administraciones públicas, exigido por el artículo 9.7 de la Carta Europea de la Autonomía Local, que si bien es respetado escrupulosamente por el Estado, no puede decirse lo mismo de todas las Comunidades Autónomas. La generalización de fondos municipales no finalistas en todas las Comunidades Autónomas, constituidos esencialmente por un porcentaje suficiente de sus ingresos impositivos, deviene una verdadera exigencia del Pacto Local, dando también cumplimiento a la exigencia contenida en el artículo 142 de nuestra Constitución.

En fin, pensamos que un estudio multidisciplinar sobre las competencias de los Entes territoriales en España supondría aclarar una cuestión bien polémica y, sobre todo, facilitar a la población una mejor gestión pública, de más calidad y con menor coste.

\section{Reflexión Final}

Los Gobiernos y las Administraciones locales tienen sentido en la medida en que son capaces de atender razonablemente los asuntos públicos locales. Cuanto mejor gobiernen y administren el espacio público local al servicio de la mejora de las condiciones de vida de los vecinos, más sentido y justificación tendrán. Si, por el contrario, se convierten en instituciones que poco o nada aportan a la calidad de vida de los ciudadanos, entonces habría que poner en marcha algún proceso de reforma que los convierta en lo que deben ser.

Las Administraciones y los Gobiernos locales se justifican en la medida en que se conviertan en instituciones al servicio objetivo de los intereses generales de dimensión local. 


\section{Cadernos do Programa de Pós-Graduação em Direito/UFRGS}

http://seer.ufrgs.br/ppgdir - ISSN: 1678-5029 - E-ISSN: 2317-8558

\section{Volume VIII | Número 2 | Ano 2013}

Prestan servicios y ejercen competencias en función de las personas de su territorio. Están para los vecinos porque ciertamente son de los vecinos en cuanto que personas con necesidades colectivas.

En el marco del denominado derecho a la buena administración de los asuntos públicos, recogido ya en el artículo 41 de la Carta Europea de los Derechos Fundamentales, la existencia de Entes locales con medios suficientes para satisfacer este nuevo derecho fundamental de las personas resulta elemental. Tal derecho fundamental quedaría reducido a la nada si en los pequeños Ayuntamientos, por problemas económicos o de personal, no se pudiera contribuir al bienestar y mejora de las personas que allí conviven.

La experiencia británica de una Royal Commission en la que aportaron sus puntos de vista todos los colectivos profesionales afectados por la cuestión local permitió, durante más de diez años, buscar acuerdos y preparar una reforma que gozó del beneplácito general y que redujo sustancialmente el número de municipios con objeto de que los servicios locales se prestaran en mejores condiciones para la mejora, valga la redundancia, de las condiciones de vida de los vecinos.

La realidad es la que es. Hoy está presidida por una aguda crisis económica y financiera que afecta soberanamente al sector público, y especialmente a los Entes públicos más débiles, a los peor financiados, que son los municipios, y dentro de ellos, obviamente, los más pequeños. Por eso, la reforma local es urgente y cuanto antes comience las consecuencias serán menos dañinas para los vecinos.

Los planteamientos inmovilistas, como de costumbre, nos condenan a seguir empeorando el nivel de prestación de los servicios obligatorios y a descuidar la gestión pública de los asuntos públicos locales. Los vecinos, en tal contexto, se distancian de los electos y de las posibilidades de la participación. Es menester reformar la realidad aprovechando la legislación vigente, que ofrece distintas fórmulas para salir del atolladero. También se pueden implementar las innovaciones normativas que sean necesarias, todo ello al servicio de contar con instituciones locales que realmente puedan cumplir su función constitucional. 


\section{Cadernos do Programa de Pós-Graduação em Direito/UFRGS}

http://seer.ufrgs.br/ppgdir - ISSN: 1678-5029 - E-ISSN: 2317-8558

\section{Volume VIII | Número 2 | Ano 2013}

En este contexto, buena cosa sería proceder a un estudio en profundidad del mapa competencial de los distintos Entes territoriales. A día de hoy todavía existen muchas duplicidades y superposiciones que podrían eliminarse si dispusiéramos de mayor claridad competencial. Si tras un estudio sereno y riguroso se llegara a la conclusión de que fuera necesario modificar la Constitución para delimitar con mayor precisión las competencias del Estado, de las Comunidades Autónomas y de los Entes locales, adelante. Si, por el contrario, se concluyera que es mejor confiar estas cuestiones a los procesos de deliberación pública de manera que sea el consenso y la colaboración entre Gobiernos Administraciones públicas el que presida la solución a estos temas, adelante.

En este orden de cuestiones, también merecería la pena pensar en la idoneidad de las diputaciones provinciales para erigirse, no sólo en instancias públicas en las que la Xunta, como dispone el Estatuto, pueda delegar o confiar la ejecución de sus acuerdos de naturaleza provincial, sino en las Administraciones periféricas provinciales del propio Gobierno de la Comunidad Autónoma.

La realidad es la que es. En Galicia todos sabemos cuáles son nuestros problemas en esta materia y cuáles los caminos para iniciar su solución. Desde luego con tantos municipios de menos de 5.000 habitantes es muy difícil gestionar y administrar los espacios públicos locales razonablemente, coherentemente y al servicio de las necesidades colectivas de los vecinos. Por eso, también aquí, en nuestra Comunidad Autónoma, el Gobierno de la Xunta plantea distintas fórmulas presididas por el asociacionismo y las fusiones para luchar contra las enormes dificultades que a día de hoy presentan no pocos municipios gallegos de menos de 5.000 habitantes que no se sabe cómo pueden pagar los gastos corrientes, las nóminas y, lo que es más grave, cómo prestar los servicios municipales obligatorios. Para ello, a imagen y semejanza de lo que se plantea en otras Comunidades Autónomas, se tendrá que acudir a medidas de fomento que faciliten fusiones, mancomunidades o consorcios, en cada caso lo que sea más razonable. En este sentido, se pretende que la Comisión Galega de Delimitación Territorial, prevista en la ley gallega de Administración local de 1997, pueda revisar el mapa de planta municipal y así poder realizar estudios y propuestas de fomento para la fusión o la asociación municipal, vía mancomunidades o consorcios, y establecer ayudas económicas y técnicas, fijación de criterios 
prioritarios o especiales en la asignación de subvenciones finalistas y en la creación de un Fondo especial ad hoc para facilitar estas operaciones de unión municipal.

En la Comunidad Valenciana está previsto que la nueva ley de régimen local contemple la posibilidad de de que los pequeños municipios se asocien para afrontar determinados gastos en materia de personal. Se prevén también mancomunidades de interés preferente, un camino para que los municipios que opten por esta fórmula de asociacionismo municipal dispongan de especiales programas de fomento.

En Cataluña, como hemos señalado en el epígrafe anterior, si las medidas de impulso y fomento de las fusiones y las mancomunidades fracasarán, el Gobierno podrá poner en marcha una reorganización territorial que modifique el mapa local. Primero, pues, es menester fomentar las fusiones y el asociacionismo municipal con efectivas medidas de fomento como las que aquí hemos expuesto. Y, después, entonces, habrá que analizar lo que ha acontecido y por qué.

Si fuera posible propiciar fórmulas de integración local sin que desaparezca ningún municipio de manera que se fortalezcan los presupuestos y se puedan prestar en mejores condiciones los servicios municipales obligatorios, entonces se produciría la cuadratura del círculo. Algo que, por el momento no parece posible. Sí que es posible seguir trabajando en el fomento de mancomunidades voluntarias que presten objetivamente mejor los servicios a los vecinos y en consorcios que garanticen igualmente mejores capacidades y técnicas que redunden en la calidad de vida de los vecinos. Crear ahora nuevos Entes locales superpuestos a los ya existentes es, desde luego, en este momento, irracional. En mi opinión, lo razonable, es trabajar desde las estructuras reales y buscar las mejores soluciones posibles. En todo caso, el asociacionismo voluntario no es mal camino hacia fusiones que hagan posible de verdad una mejor prestación de los servicios públicos municipales a los vecinos.

\section{BIBLIOGRAFIA}

Informe del Círculo de Empresarios de Galicia, Un nuevo mapa municipal para Galicia, Cuadernos para el debate $n^{\circ}$ 16, Club Financiero de Vigo, 2009.

X.L. BARREIRO RIVAS, Hacia una nueva estructura municipal, en R. RODRIGUEZ GONZÁLEZ, Reformar la Administración territorial, Netbiblo, A Coruña, 2009, páginas 3 a 19. 
M. CADAVAL SAMPEDRO, Las aglomeraciones urbanas desde la perspectiva de la Hacienda Pública, Instituto de Estudios Fiscales, Documento nº 19/04, Madrid, 2001.

C. ESCUIN PALOP, en S. MUÑOZ MACHADO (Director), Tratado de Derecho Municipal, Civitas, Madrid, 2003, páginas

J.L. MEILÁN GIL, Municipio y estructuras políticas, en R. RODRIGUEZ GONZÁLEZ, Reformar la Administración territorial, Netbiblo, A Coruña, 2009, páginas 21 a 39.

A.C. OLIVEIRA, O marco administrativo local em Portugal, en R. RODRÍGUEZ GONZÁLEZ, Reformar la Administración territorial, Netbiblo, A Coruña, 2009, páginas 43 a 65.

C. LÓPEZ ARRIBAS, La reorganización territorial: hacia unos Ayuntamientos eficientes y viables: la fusión selectiva de municipios, en R, RODRÍGUEZ GONZÁLEZ, Reformar la Administración territorial, Netbiblo, A Coruña, 2009, páginas 185 a 199.

E. ORDUÑA PRADA, El municipio como marco relacional, en R, RODRIGUEZ GONZÁLEZ, Reformar la Administración territorial, Netbiblo, A Coruña, 2009, páginas 99 a 125,

F. SOSA WAGNER, Creación, fusión y supresión de municipios, en R. RODRÍGUEZ GONZÁLEZ, Reformar la Administración territorial, Netbiblo, A Coruña, 2009, páginas 69 a 95.

F. SOSA WAGNER, Manual de Derecho Local, Aranzadi, Pamplona, 2001.

R. RODRIGUEZ GONZALEZ (Director), Reformar la Administración territorial, Netbiblo, A Coruña, 2009.

R. RODRIGUEZ GONZÁLEZ, Ayuntamiento de Deza: estructura organizativa de una utopía, en R. RODRÍGUEZ GONZÁLEZ, Reformar la Administración territorial, Netbiblo, A Coruña, 2009, páginas 203 a 227.

R. RODRÍGUEZ GONZÁLEZ, Territorio y gobierno local en España: un planteamiento de reestructuración por fusión como realidad necesaria, Civitas, Madrid, 2005 


\section{Cadernos do Programa de Pós-Graduação em Direito/UFRGS}

http://seer.ufrgs.br/ppgdir - ISSN: 1678-5029 - E-ISSN: 2317-8558

E. VARELA ALVAREZ, El nuevo minicipalismo gallego. ¿Administraciones versus gobiernos locales?, en R. RODRÍGUEZ GONZÁLEZ, Reformar la Administración territorial, páginas 169 a 181 .

Submissão: 21/12/2013

Aceito para Publicação: 21/12/2013 